\title{
The Mispricing Return Premium
}

\author{
Michael J. Brennan* \\ Ashley W. Wang ${ }^{\dagger}$
}

June 2007

\footnotetext{
${ }^{*}$ We are grateful to Yakov Amihud, David Hirshleifer, Weimin Liu, Jeff Pontiff, and Avanidhar Subrahmanyam for helpful comments on an earlier version of the paper which was circulated under the title Asset Pricing and Mispricing. We also thank discussants (Andrew Ang, Anthony Lynch, and Ronnie Sadka) and participants in seminars at the Conference of Barclays Global Investors, Financial Economics and Accounting at Atlanta, HKUST, SEC, Singapore Management University, Stockholm School of Economics, UC Davis, UC Irvine, UCSD, University of Georgia at Athens, University of Vienna, and the 2007 WFA meeting.

${ }^{\dagger}$ Michael Brennan is Emeritus Professor at the Anderson School, UCLA and Distinguished Visiting Professor at the Department of Accounting and Finance, Manchester University. Ashley Wang is Assistant Professor at the Paul Merage School of Business, University of California, Irvine. Corresponding Author: Finance Area, Paul Merage School of Business, University of California at Irvine, Irvine, CA 92697. E-mail: ashwang@uci.edu.
} 


\begin{abstract}
We show that, when stock prices are subject to stochastic mispricing errors, expected rates of return may depend not only on the fundamental risk that is captured by a standard asset pricing model, but also on the type and degree of asset mispricing, even when the mispricing is zero on average. Empirically, the mispricing induced return premium, either estimated using a Kalman filter or proxied by the volatility and variance ratio of residual returns, is shown to be significantly associated with realized risk adjusted returns.
\end{abstract}




\section{Introduction}

In this paper we consider the implications of Jensen's inequality for stock prices and expected rates of return in markets which are less than perfectly efficient. In particular we show that, for securities which are subject to stochastic mispricing relative to a given equilibrium asset pricing model, it is likely that either their prices will fail to be unconditionally rational or their returns will fail to be unconditionally rational, or both. By unconditionally rational prices we mean prices whose unconditional expectations are consistent with the fundamental asset pricing model, and by unconditionally rational returns we mean returns whose unconditional expectations are consistent with the fundamental asset pricing model. For example, a stock that on average trades at $100 \%$ of its fundamental value, but whose price fluctuates about the fundamental value, will have an average return that is higher than that predicted by the model that determines the fundamental value. Our use of Jensen's inequality to impose restrictions on prices and returns follows earlier applications of Jensen's inequality to expectations based theories of asset pricing. For example, Siegel's (1972) paradox, which relies on the inequality, implies that if foreign exchange rates are stochastic and the forward exchange rate between currency $\mathrm{A}$ and currency $\mathrm{B}$ is equal to the expected future spot rate, then the forward rate of exchange between currency B and currency A cannot also be equal to the expected future spot rate: there must be a risk premium associated with at least one of the forward rates. Similarly, Cox et al. (1981) use Jensen's inequality to show pair-wise inconsistency between three traditional definitions of the expectations theory of the term structure of interest rates.

Our analysis follows immediately from Jensen's inequality because price is a non-linear function of expected return, so that if one variable is subject to random error then the expectation of the other variable will be biased. It is of course possible that neither prices nor expected returns are unconditionally rational. If prices are unconditionally rational, then the premium in unconditional expected returns due to mispricing is shown to depend on the volatility and first order autocorrelation of the mispricing.

Since the simple analysis underlying our empirical work relies only on Jensen's inequality, it is model-independent. We do not make specific assumptions about the cause of mispricing, 
so that our analysis applies to the models such as those of De Long et al. (1990), Madhavan and Smidt (1993), and Campbell and Kyle (2001), in which mispricing arises as the result of noise trader demands. Taking mispricing as given, we explore its empirical consequences for average returns. Since the mispricing is not directly observable, we use proxies for the mispricing return premium. Our empirical tests reveal that portfolios formed on the basis of these proxies have significantly different returns after adjusting for risk. This is consistent with at least a part of the Jensen's inequality effect being impounded in returns.

The remainder of the paper is organized as follows. In Section 2 we discuss how this paper is related to prior literature. Section 3 presents a simple one period example which shows that, in the presence of random security mispricing, unconditionally rational prices are inconsistent with unconditionally rational returns. Section 4 analyzes the return bias introduced by random mispricing in a general intertemporal context. Section 5 presents empirical results relating returns to proxies for the mispricing return premium, and Section 6 concludes.

\section{$2 \quad$ Related Literature}

This paper is at the intersection of the empirical market efficiency and the asset pricing literatures, which often overlap but to our knowledge have not been integrated. On the one hand, tests of classical asset pricing models such as the CAPM, CCAPM, or ICAPM implicitly rely on an assumption of market efficiency which permits the substitution of realized returns for expected returns. On the other hand, most tests of market efficiency rely on some model of equilibrium returns. ${ }^{1}$ However, there is now extensive evidence that common stocks are mispriced relative to these models, ${ }^{2}$ although the reasons for the pricing discrepancies remain in dispute. For example, de Bondt and Thaler $(1985,1987)$ find long run reversals of prior stock price changes which they interpret as corrections of prior over-reactions to news, while Jegadeesh and Titman (1993) among others find positive autocorrelation of individual stock returns at the 6-12 month horizon, which is consistent

\footnotetext{
${ }^{1}$ Cf. Fama (1991, p1575): 'Thus, market efficiency per se is not testable. It must be tested jointly with some model of equilibrium, an asset-pricing model.'

${ }^{2}$ French and Roll (1986) suggest that on average 4 to $12 \%$ of the daily return variance of common stock returns is due to mispricing.
} 
with the slow adjustment to firm specific news documented in a large number of studies. Jegadeesh and Titman (1995) also find evidence that stock prices tend to over-react to firm specific information. Brennan et al. (1993) show that the speed of adjustment of prices to market wide information depends on firm size and analyst following. Lee and Swaminathan (2000) find that low (high) trading volume stocks tend to be under- (over-) valued by the market. There is also an extensive accounting literature demonstrating that stock market prices do not fully reflect the fundamental information contained in accounting statements. ${ }^{3}$ Finally, recent research relates stock returns to non-fundamental information: Pastor and Stambaugh (2003), Acharya and Pedersen (2005) and Sadka (2006) show that stock returns are affected by (or at least covary with) the state of stock market liquidity, while Amihud (2002) shows that unanticipated increases in market illiquidity reduce the level of stock prices. Lee et al. (1991), Swaminathan (1996) (more circumspectly) and Baker and Wurgler (2006) argue that stock prices are affected by the state of 'sentiment'.

Our analysis is also related to an early literature on the implications of security mispricing for measuring rates of return, including Blume and Stambaugh (1983) and Roll (1983), who are concerned with the effects of daily auto-correlations and the bid-ask bounce on measured rates of return. ${ }^{4}$ More recently, Liu and Strong (2006) analyze the effects of portfolio rebalancing assumptions on reported returns. Other recent contributions include Bessembinder and Kalcheva (2006), and Arnott et. al. (2006). Bessembinder and Kalcheva (2006) are concerned with the return bias induced by the bid-ask spread which causes iid pricing errors. We analyze a more general pricing error structure, and find empirically that the greatest return premium arises for stocks with positively correlated pricing errors which cannot be caused by simple bid-ask bounce, although it could be consistent with the dealer inventory behavior described by Madhavan and Smidt (1993); these authors show that the price set by the specialist departs from her best estimate of fundamental value by an amount that depends on the level of specialist inventories which follows a slow mean-reverting process ${ }^{5}$. Arnott et. al. (2006) use calibration to show that mispricing can potentially account for size and value effects in asset pricing. In contrast, we estimate the mispricing return

\footnotetext{
${ }^{3}$ For examples, see Sloan (1996) and Mohanram (2004).

${ }^{4}$ See also Canina et al (1998).

${ }^{5}$ See also Hendershott and Seasholes (2007)
} 
premium directly and show that it is related to risk adjusted returns.

The analysis in this paper has implications for studies that find significant relations between stock returns and variables that may be proxies for the mispricing return premium we consider. Measures of the cost of transacting such as the bid ask spread or Kyle (1985) $\lambda$ are likely to be positively associated with the magnitude of pricing errors since transactions costs impede arbitrage. This suggests that a part of the approximately $7 \%$ return differential between high and low liquidity portfolios documented in several studies ${ }^{6}$ may be attributable to this mispricing return premium. The mispricing return premium also provides an alternative explanation for the excess returns found to be associated with idiosyncratic volatility by Malkiel and Xu(2006) and Spiegel and Wang (2006), since stocks with high idiosyncratic volatility tend to have a high mispricing return premium. Similarly, the sensitivity of stock returns to variables that have common effects on stock prices but not fundamental values, such as market liquidity or sentiment, will affect the volatility of mispricing and hence the mispricing return premium. Thus a part of the the annual return premium of around $7.5 \%$ between high and low liquidity beta portfolios reported by Pastor and Stambaugh (2003) may be attributable to the mispricing return premium. Finally, a return premium of the type that Hou and Moskowitz (2005) have found to be associated with slow adjustment to (market-wide) information is consistent with a model in which prices are unconditionally rational but adjust slowly to new information, since these stocks will offer a mispricing return premium.

\section{A Simple Example}

Consider an asset whose payoff at the end of one period is $\tilde{X}$, and denote its fundamental price by $P^{*}$. Then

$$
P^{*}=\frac{E[\tilde{X}]}{1+r^{*}}
$$

where $r^{*}$ is the equilibrium expected rate of return on the security according to some given pricing model. Let $P \equiv P^{*} \tilde{Z}$ denote the market price of the security, where $\tilde{Z}$ is a random variable which is independent of the payoff $\tilde{X}$. Then the mispricing of the security relative

\footnotetext{
${ }^{6}$ For an extensive survey of the research on liquidity and asset pricing see Amihud et al. (2005).
} 
to the given model is written as $P^{*}(\tilde{Z}-1)$. If $\tilde{Z}$ has mean unity then we say that the price is unconditionally rational. Let $\tilde{R}$ denote the realized rate of return on the security. Then:

$$
1+\tilde{R}=\frac{\tilde{X}}{P}=\frac{\tilde{X}}{P^{*} \tilde{Z}}=\frac{\tilde{X}\left(1+r^{*}\right)}{E[\tilde{X}] \tilde{Z}}
$$

Taking expectations, we have:

$$
E[1+\tilde{R}]=\left(1+r^{*}\right) E\left[\frac{1}{\tilde{Z}}\right]>1+r^{*}
$$

Thus the unconditional expected return on the security exceeds the equilibrium expected return, $r^{*}$, by what we have called a 'mispricing return premium' so long as the price is unconditionally rational so that $E[\tilde{Z}]=1$. Conversely, if the returns are unconditionally rational so that $E[\tilde{R}]=r^{*}$, then $E[\tilde{Z}]>1$ if $\operatorname{var}(\tilde{Z})>0$ so that there is a positive mispricing price premium.

\section{General Structure}

Now consider an arbitrary multi-period setting in which the security pays a dividend of $D_{t}$ at the end of period $t$ and denote the market price at the beginning of the period by $P_{t}$. We contrast the market price with the fundamental price, $P_{t}^{*}$, which is the price according to some given asset pricing model. We write $P_{t} \equiv P_{t}^{*} Z_{t}$. We shall assume throughout that market prices are strictly positive and impose the further restriction that $z \equiv \ln Z$, the $\log$ of the 'market pricing multiple', $Z$, is a time-homogeneous stationary process.

Then we can write $1+R_{t}$ the (gross) market return on the security in period $t$ as

$$
\begin{aligned}
1+R_{t} \equiv \frac{P_{t+1}^{*} Z_{t+1}+D_{t}}{P_{t}^{*} Z_{t}} & =\frac{P_{t+1}^{*}}{P_{t}^{*}} \frac{Z_{t+1}}{Z_{t}}+\frac{D_{t}}{P_{t}^{*} Z_{t}} \\
& \equiv\left(1+R_{t}^{* g}\right)\left(1+\frac{\Delta Z_{t}}{Z_{t}}\right)+\delta_{t}^{*}\left(1 / Z_{t}\right)
\end{aligned}
$$

where $\Delta Z_{t} \equiv Z_{t+1}-Z_{t}, R^{* g} \equiv\left(P_{t+1}^{*}-P_{t}^{*}\right) / P_{t}^{*}$ is the 'capital gain return' based on the fundamental price, and $\delta_{t}^{*} \equiv D_{t} / P_{t}^{*}$ is the dividend yield based on the fundamental price. Note that the return based on the fundamental price, $R_{t}^{*}$ is equal to $R_{t}^{* g}+\delta_{t}^{*}$.

Then the market return, $R_{t}$, is related to the fundamental return, $R_{t}^{*}$, by:

$$
R_{t}=R_{t}^{*}+R_{t}^{* g} \frac{\Delta Z_{t}}{Z_{t}}+\frac{\Delta Z_{t}}{Z_{t}}-\delta_{t}^{*}\left(1-1 / Z_{t}\right)
$$


Assume for simplicity that the mispricing variable $\tilde{Z}_{t}$ is independent of the (fundamental) dividend yield $\delta_{t}^{*}$. Then, taking expectations in (5), the expected market return is related to the expected fundamental rate of return by:

$$
\begin{aligned}
E\left[R_{t}\right] & =\left[R_{t}^{*}\right]+E\left[R_{t}^{* g}\right] E\left[\frac{\Delta Z_{t}}{Z_{t}}\right]+\operatorname{cov}\left(R_{t}^{* g}, \frac{\Delta Z_{t}}{Z_{t}}\right) \\
& +E\left[\frac{\Delta Z_{t}}{Z_{t}}\right]-E\left[\delta_{t}^{*}\right] E\left[1-1 / Z_{t}\right]
\end{aligned}
$$

The second term in (6) is small since it is a product of the expected capital gain based on fundamental prices and the expected mispricing rate of return, $E\left[\Delta Z_{t} / Z_{t}\right]$. For simplicity, we ignore it. Then, approximating the fifth term by a Taylor expansion, we write the relation between the expected market return and the expected fundamental return as:

$$
\begin{aligned}
E\left[R_{t}\right] & \approx E\left[R_{t}^{*}\right]+E\left[\frac{\Delta Z_{t}}{Z_{t}}\right]+\operatorname{cov}\left(R_{t}^{* g}, \frac{\Delta Z_{t}}{Z_{t}}\right)-E\left[\delta_{t}^{*}\right]\left[1-\frac{1}{E[Z]}\left(1+\frac{\sigma_{Z}^{2}}{E[Z]^{2}}\right)\right] \\
& \equiv E\left[R_{t}^{*}\right]+B_{1}+B_{2}+B_{3}
\end{aligned}
$$

where $\sigma_{Z}$ is the standard deviation of the stationary distribution of $Z, B_{1} \equiv E\left[\frac{\Delta Z_{t}}{Z_{t}}\right]$, etc., and $B \equiv B_{1}+B_{2}+B_{3}$ denotes the premium in the unconditional expected return associated with mispricing relative to the asset pricing model that determines the fundamental. price.

If $B_{2} \equiv \operatorname{cov}\left(R_{t}^{* g}, \frac{\Delta Z_{t}}{Z_{t}}\right)>0$, the mispricing is associated with over-reaction since the pricing error tends to increase when fundamentals improve and to decrease when they deteriorate. If $B_{2}<0$, the mispricing is associated with slow adjustment since an increase (decrease) in the fundamental price is accompanied on average by a smaller proportional change in the market price. Daniel et al. (1998) demonstrate that both over-reaction and under-reaction to information can occur as a result of investor overconfidence about the precision of private information and biased self-attribution. If $B_{2}=0$, the mispricing is unrelated to fundamentals.

$B_{3} \equiv-E\left[\delta_{t}^{*}\right]\left[1-\frac{1}{E[Z]}\left(1+\frac{\sigma_{Z}^{2}}{E[Z]^{2}}\right)\right]$ reflects the impact of mispricing on the dividend yield. It will be zero if the fundamental dividend yield is zero, and under the unconditional rational pricing assumption that $E[Z]=1, B_{3}$ is likely to be small. When $E[Z]=1$, $B_{3}=E\left[\delta_{t}^{*}\right] \sigma_{Z}^{2}>0$, so that if the standard deviation of the mispricing is 0.3 and $\sigma_{Z}^{2}=0.09$, 
then $B_{3}$ will be of the order of $0.2 \%$ for a stock with a $2 \%$ (fundamental) dividend yield. $B_{3}$ will also be positive when there is average underpricing so that $E\left[Z_{t}\right]<1$. However, if there is overpricing on average, then $B_{3}$ can be negative, although it is bounded below by the (negative of the) fundamental dividend yield. For example, if there is $100 \%$ overpricing $\left(E\left[Z_{t}\right]=2\right), B_{3} \approx-1 \%$ per year under the same assumptions for $\sigma_{Z}$ and $E\left[\delta_{t}^{*}\right]$.

Note that we can write $\Delta Z / Z=e^{\Delta z}-1$, where $z \equiv \ln Z$. Then it follows from the convexity of the exponential function and the assumed time-homogeneity and stationarity of $z$ that $B_{1} \equiv E[\Delta Z / Z]>0$, and we have the following conditions on the sign of the premium, $B$, associated with mispricing:

Lemma 1 Under unconditional rational pricing, if mispricing is associated with overreaction or is unrelated to news, then the mispricing return premium is strictly positive.

If the premium is associated with slow adjustment, then the sign of the premium is indeterminate.

Under unconditional rational pricing $B_{3}$ is small and positive, and simulations suggest that $B_{2}$ is likely to be very small when the mispricing is due to slow adjustment, so that the mispricing return premium will be mainly due to $B_{1}$. There is therefore a presumption under unconditional rational pricing that the total premium will be positive. Note that when the fundamental dividend yield is zero, $B_{3}=0$, and, neglecting $B_{2}$, the total premium will be positive whether or not prices are unconditionally rational.

Consider now the determinants of the premium element $B_{1}$. Assume that the unconditional distribution of $\Delta z \equiv \ln Z_{t+1}-\ln Z_{t}$ is normal with parameters $\left(\mu_{\Delta z}, \sigma_{\Delta z}\right)$. Since $z$ is a stationary random variable, $\mu_{\Delta z}=0$ and

$$
B_{1}=e^{\frac{1}{2} \sigma_{\Delta z}^{2}-1}
$$

Now we can always write:

$$
\Delta z_{t} \equiv z_{t}-z_{t-1}=\left(\rho_{1}^{z}-1\right) z_{t-1}+\eta_{t}
$$

where $\rho_{1}^{z}$ is the first order autocorrelation of $z$, and $\eta_{t}$ is a zero mean normally distributed error term that is independent of $z_{t-1}$. Then:

$$
B_{1}=e^{\left(1-\rho_{1}^{z}\right) \sigma_{z}^{2}}-1 .
$$


where $\sigma_{z}^{2}$ is the unconditional variance of $z$. Thus the mispricing return premium is decreasing in the first order autocorrelation of $z$; ceteris paribus, mispricing that is rapidly eliminated or even reversed will lead to a higher premium. The premium is also increasing in the unconditional variance of the mispricing.

We have assumed in our analysis that the (log of) mispricing, $z$, follows a time-invariant stationary process. It is worth considering also the possibility that $z$ follows a process that depends on time or other state variables. It is possible for example that young firms tend to have a high volatility of mispricing because of the difficulty of valuing them; and that this high volatility is accompanied by a high average level of mispricing, and that both the mean and volatility of mispricing tend to decline as the firm matures. In this case we might assume that $\Delta z(t) \equiv \ln Z_{t+1}-\ln Z_{t}$ is normal with parameters $\left(\mu_{\Delta z}(t), \sigma_{\Delta z}(t)\right)$, where $t$ denotes calendar time. Now it is quite possible to choose these parameters so that $B_{1}=0$, and for the mispricing return premium to be zero (unconditional rational returns). ${ }^{7}$ Hence the existence of a mispricing return premium is essentially an empirical question which we investigate in the following section by constructing portfolios using ex-ante estimates of $B_{1}$ that are derived under the assumption of a time-homogeneous process for $z$.

\section{Empirical Analysis}

In this section, we present evidence that risk adjusted returns are related to proxies for the mispricing return premium. Our analysis is based on the general model of mispricing presented in Section 4 . We focus on the premium element $B_{1} \approx\left(1-\rho_{1}^{z}\right) \sigma_{z}^{2}$, and assume that $B_{2}$ is zero, because $B_{2} \neq 0$ implies non-zero correlation between the innovations in mispricing and fundamental returns which causes identification problems in our Kalman filter estimation of $B_{1}$; this is discussed in Watson (1986), and Harvey (1989). We also ignore the dividend yield related component $B_{3}$, which is likely to be small. In the following it will be convenient to refer to $B_{1}$ as the theoretical mispricing return premium. It should be understood that it will be the true premium only if $B_{2}=B_{3}=0$, and $z$ follows a

\footnotetext{
${ }^{7}$ Pastor and Veronesi (2003) develop a model in which the ratio of the market price to the book value declines with firm maturity as a result of learning about firm profitability. Mispricing with unconditional rational returns would accentuate this decline.
} 
time-invariant process.

We use two approaches to proxy for $B_{1}$. First, we use a Kalman filter to estimate the theoretical mispricing return premium, assuming that individual security mispricing follows a simple AR1 process. The AR1 assumption is restrictive, and does not allow for positive short term autocorrelation in returns: as a result, our estimation algorithm did not converge for a significant number of stocks. ${ }^{8}$ Therefore our second approach uses the volatility and variance ratio of residual returns to proxy for mispricing. The variance ratio, which is approximately a linear combination of sample autocorrelations (Cochrane, 1988), does not require us impose any structure on the mispricing process. To the extent that our approach mis-estimates the total mispricing return premium, we are less likely to find evidence against the null hypothesis that average security returns are unaffected by mispricing.

\section{$5.1 \quad$ Data}

The primary data that we use are the monthly returns on all stocks registered on the NYSE, AMEX and NASDAQ from January 1962 to December 2004, which are taken from CRSP. We include only common shares, and exclude preferred stocks, ADR's, REIT's, etc. To alleviate the potential influence of 'stale prices', we include only observations with positive trading volume and with valid month-end closing prices. We also filter out penny stocks. We use as risk factors monthly returns on the 3 Fama-French factors, and the momentum factor of Carhart (1997); these, together with 1-month Tbill returns, are taken from Ken French's website. ${ }^{9}$ We use data on book values from COMPUSTAT, and on prices, market capitalization and share turnover from CRSP. ${ }^{10}$ Finally, in some of our regressions we use data on analyst following and the dispersion of analysts' forecasts of earnings 1 to 2 quarters ahead, which are taken from IBES.

\footnotetext{
${ }^{8}$ We also developed an estimate of the premium based on an AR2 process for the mispricing. See Khil and Lee (2002). The empirical results for this model are qualitatively similar to those for the AR 1 process. However, they are less significant, which is probably due to the difficulty of identifying the parameters of the more complex model.

${ }^{9}$ http : //mba.tuck.dartmouth.edu/pages/faculty/ken.french/datalibrary.html

${ }^{10}$ To address the issue of inter-dealer trading in OTC markets, we multiply the NASDAQ trading volume by 0.6, following Atkins and Dyl (1997).
} 


\subsection{AR1 Estimates of Mispricing}

In order to identify mispricing, the 'fundamental return', $R^{*}$, was assumed to follow an ex-post version of the Fama-French (1993) 3-factor model (FF3):

$$
R_{i, t}^{*}-R_{F, t}=b_{i}\left(R_{M, t}-R_{F, t}\right)+c_{i} S M B_{t}+d_{i} H M L_{t}+\epsilon_{i, t}
$$

where $R_{i, t}^{*}$ is the fundamental return on stock $i$ in month $t, R_{F, t}$ is the riskless interest rate, and $R_{M, t}, S M B_{t}, H M L_{t}$ are the Fama-French factors. Then, to a first order approximation, the market return, $R_{i, t}$ is given by:

$$
R_{i, t}-R_{F, t}=\alpha_{i}+b_{i}\left(R_{M, t}-R_{F, t}\right)+c_{i} S M B_{t}+d_{i} H M L_{t}+e_{i, t}
$$

where $e_{i, t}=z_{i, t}-z_{i, t-1}+\epsilon_{i, t}$, and $z_{i, t}$ is (approximately) the log of the mispricing factor at time $t$, and $\alpha_{i}$ corresponds to the mispricing return premium effect.

Following Poterba and Summers (1988), the log of the mispricing was assumed to follow the $\mathrm{AR}(1)$ process:

$$
z_{t}=\phi_{1} z_{t-1}+\eta_{t}
$$

Then, following Khil and Lee (2002), a Kalman filter was used to estimate the logarithm of the mispricing factor, $z_{t}$, and the parameters of the mispricing process, $\phi_{1}$ and $\sigma_{\eta}$, for each security, from the FF3 residual returns, $e_{i, t}$. The observation equation for the Kalman filter is:

$$
e_{t}=z_{t}-z_{t-1}+\epsilon_{t}
$$

and the transition equation is $z_{t}=\phi_{1} z_{t-1}+\eta_{t}$. Given the estimates from the Kalman filter, the estimated theoretical mispricing return premium is:

$$
\hat{B}_{1} \approx\left(1-\hat{\phi}_{1}\right) \hat{\sigma}_{z}^{2}=\frac{\hat{\sigma}_{\eta}^{2}}{1+\hat{\phi}_{1}}
$$

Details of the Kalman filter algorithm are given in the Appendix.

The parameters of the mispricing process and the theoretical mispricing return premium, $\hat{B}_{1}$, were estimated at the beginning of January of each year from 1967 to 2004 for all stocks with at least 36 monthly returns using the FF3 residual returns estimated over the previous 60 months as available. 


\subsubsection{Mispricing and Returns}

Although the focus of this paper is on the mispricing return premium, it is useful to confirm the validity of our estimates of mispricing, $z_{i, t}$, yielded by the Kalman filter. For this purpose the (log) mispricing was estimated every month for all securities with at least 36 monthly returns using the FF3 residual returns estimated over the previous 60 months as available so that there is no 'look-ahead' bias in the estimation. Then securities were assigned to one of ten portfolios in month $t$ on the basis of $\hat{z}_{t-1}$ and the equally weighted return on the portfolio was calculated. In addition, the spread between the returns on the high and low $z$ portfolios was computed. Panel A of Table 1 reports for each portfolio the average value of $\hat{z}_{i, t-1}$, the average monthly return, and the intercept from a regression of the portfolio excess returns on the three Fama-French factors (FF3 $\alpha$ ). The average value of $\hat{z}_{t-1}$ is -6.37 for the low $z$ portfolio and 7.44 for the high $z$ portfolio, so that estimated mispricing tends to fall in the range of $\pm 6-7 \%$. Both the average returns and the FF3 $\alpha$ 's vary monotonically and inversely with $\hat{z}_{t-1}$ which is to be expected as market prices revert towards fundamental values. FF3 $\alpha$ for the low(high) $z$ portfolio is $0.87 \%(-0.67 \%)$ per month, and the t-statistic on the spread between these returns is close to 9 . Thus $\hat{z}_{t-1}$ seems to capture a significant element of mispricing. To see whether this is merely another version of the short run reversal effect noted by Jegadeesh (1990) the analysis was repeated. This time the securities were sorted into 25 portfolios, first into quintiles on the basis of the lagged monthly return, $R_{t-1}$, and then within each quintile into a further five portfolios based on $\hat{z}_{t-1}$. Panel B of Table 1 shows that $z$ carries significant information about future returns beyond the reversal effect captured by $R_{t-1}$ : the return associated with $z$ is of the order of $47-121 b p$ per month and the t-statistics on the spread between high and low $z$ portfolios are in the range $3-9$ for the different $R_{t-1}$ quintiles.

\subsubsection{Mispricing and Firm Characteristics}

To confirm that our ex-ante estimates of the theoretical mispricing return premium, $B_{1}$, are related to fundamental firm characteristics, we regress the Kalman filter estimates of the first order autocorrelation, $\phi_{1}$, the variance of the mispricing variable, $\sigma_{z}^{2}$, and the 
resulting premium estimate, $B_{1}$, on firm characteristics that may be expected to influence mispricing. At the end of each year from 1976 to 2003 , we regress the estimates of $\phi_{1}, \sigma_{z}^{2}$, and $B_{1}$ that have been obtained using residual returns over the previous 5 years on the year-end characteristics: firm size, book-to-market ratio, share price, share turnover, the logarithm of the number of analysts following the firm, and the dispersion of the analyst earnings forecasts for the next 1 to 2 quarters. Only firms that are followed by at least two analysts are included in the regressions. Table 2 reports the time series average of the coefficients, and HAC adjusted $t$-statistics.

Intuition suggests that small firms will be more subject to mispricing, and we find a strong negative relation between the variance of mispricing and firm size. Moreover, for small firms the mispricing tends to be more transient (low $\phi_{1}$ ), which also increases $B_{1}$. The net effect is that $\hat{B}_{1}$, the estimated theoretical mispricing return premium, is significantly negatively related to firm size. Book-to-market ratio is negatively associated with the variance of mispricing, and positively associated with $\phi_{1}$, the persistence of mispricing. As a result, growth firms tend to have more transient and volatile mispricing, and therefore a higher mispricing return premium. A lower stock price is associated with more volatile and more transient mispricing, and therefore with a higher return premium. The effect of turnover is to reduce the persistence of mispricing but to increase the variance of the mispricing, and the net effect is to increase the return premium. We had expected the number of analysts following a stock to reduce the variability of mispricing, and the dispersion of analysts forecast to increase the variability of mispricing. While the sign of the coefficient on the number of analysts is consistent with the expectations, the coefficient is not significant, and the net effect of the number of analysts on the return premium is insignificant. On the other hand, the dispersion of analysts' forecast is marginally significantly associated with variability of the mispricing and therefore with the return premium, and the direction of the effect is consistent with prior intuition. Our results are generally consistent with the findings of Kumar and Lee(2006) that the returns on small firms with low stock prices have higher loadings on a measure of retail investor sentiment, which induces transient mispricing. 


\subsubsection{Theoretical Mispricing Return Premium and Realized Returns}

In order to assess the relation between our estimates of the theoretical mispricing return premium, $B_{1}$, and risk-adjusted returns, stocks were assigned in January of each year from 1967 to 2004 to one of ten equal size portfolios according to the previous month end mispricing return premium estimate, $\hat{B}_{1}$. An equal investment was assumed to made in each stock in the portfolios at the beginning of the year and no rebalancing was assumed within the year. ${ }^{11}$ The first portfolio allocation occurs at the end of December 1966, and the last at the end of December 2003. The post-ranking returns were then linked across time, yielding a time series of returns for each decile from January 1967 to December 2004. On average, there are about 200 stocks within each portfolio, and at no time is the number of stocks in a portfolio less than 110 .

Panel A of Table 3 reports the characteristics of the portfolios. The 10-1 spread corresponds to a zero-investment portfolio that is long in the high premium portfolio and short in the low premium portfolio. Portfolio ' $N C V$ ' contains stocks for which the Kalman Filter did not converge. Betas of the portfolios were obtained by regressing excess returns on the portfolios on the three FF factors and the momentum factor of Carhart (1997). The high $\hat{B}_{1}$ portfolios tend to have higher loadings on the market and on $S M B$, and lower loadings on $H M L$. The estimated theoretical mispricing return premium is strongly related to firm size as we found in Table 2, which is also consistent with the pattern of loadings on $S M B$ : the relation is almost perfectly monotonic and the firms in the high premium portfolio are less than $1 / 20$ th of the size of firms in the low premium portfolio. The lower loadings of high premium portfolios on $H M L$ are also consistent with the finding in Table 2 that the return premium is higher for growth firms. The size composition of decile portfolios is consistent with the relation between firm size and the return premium reported in Table 2. There is no relation between the loadings on $M O M$ and the premium. The average firm in Portfolio $N C V$ has characteristics that are close to the average of all firms, except for $\beta_{H M L}$, which

\footnotetext{
${ }^{11}$ Since mispricing is most likely to found among small stocks, we use an equal weighting scheme to compensate for the over-representation of large, liquid, and closely followed stocks that are less likely to be subject to mispricing. Acharya and Pedersen (2005), Amihud (2002), and Chordia et al. (2000) adopt a similar strategy in their studies of liquidity and asset pricing. Liu and Strong (2006) show that monthly rebalancing can lead to significant biases in average returns, especially for small, low price, value and loser stocks.
} 
is close to that of the high premium portfolio.

The average estimated AR1 coefficient, $\phi_{1}$, increases from -0.13 for the low premium portfolio to 0.32 for the high premium portfolio; the latter corresponds to a half life for mispricing innovation of 0.6 months, or about 12 trading days. ${ }^{12}$ Note that if the mispricing were due solely to an iid bid-ask spread, $\phi_{1}$ would be equal to zero. The average volatility of mispricing, $\sigma_{z}$, is monotonic, ranging from $1.08 \%$ for the low premium portfolio to $16.70 \%$ for the high premium portfolio. Finally, the estimated volatility of the fundamental return, $\sigma_{\epsilon}$, is almost monotonically increasing across portfolios, so that the firms with the most (fundamental) idiosyncratic risk tend to be those most subject to mispricing. The estimated annualized theoretical mispricing return premium runs from 14 bp to over $16 \%$. Note that expression (13) implies that the estimated premium is non-negative. For the first six portfolios the premium estimates are moderate, reaching $1.98 \%$ for portfolio 6 . However, they increase rapidly for the last four portfolios, more than quadrupling between portfolios 8 and 10.

Panel B of Table 3 contains our basic results. The average returns of the portfolios are almost monotonically increasing with the estimated theoretical mispricing return premium, $B_{1}$, and the spread between the high and low premium portfolios is almost $1 \%$ per month. The excess returns on the decile portfolios were regressed in turn on the excess market returns, on the $3 \mathrm{FF}$ factors, and on the 4 Carhart factors. The intercepts from these regressions provide estimates for risk-adjusted returns, which are reported in Panel B. There is a clear tendency for the risk-adjusted returns to increase with the premium estimates for all three risk adjustment benchmarks. The correlations between the return premium estimates and both the FF3 and the FF4 adjusted returns are over 0.96. The spread in FF3 adjusted return between the high and low premium portfolios is 72 bp per month, or $8.64 \%$ per year, and is highly significant. These results provide strong evidence that realized stock returns contain an economically and statistically significant mispricing return premium.

We now consider some robustness tests of these basic results. Figure 1A shows that the positive association between the theoretical mispricing return premium estimates and the

\footnotetext{
${ }^{12}$ This compares with a half life of 2-22 trading days for dealer inventory innovations estimated by Madhavan and Smidt (1993): in their model, the deviation between price and fundamental value is proportional to the dealer inventory.
} 
realized FF3 adjusted returns is dominated by the returns on the high premium portfolio. To ensure that our results are not driven by this extreme portfolio, we repeated the analysis forming portfolios after winsorizing away the stocks in this top decile. Figure 1B shows that the positive association between risk adjusted returns and premium estimates is maintained in the reduced sample. Panel A of Table 4 shows that the effect of winsorization is to halve the average return spread and to reduce the FF3 risk adjusted spread from 72 bp to 28 bp per month. Both spreads remain statistically significant.

As a further robustness test, the analysis was repeated leaving one month between the end of the Kalman filter estimation and the portfolio formation. The Kalman filter was estimated using data ending in November of each year, and the portfolios were formed at the end of December each year. The result reported in Panel B of Table 4 is to increase return spreads by 15 to 23 bp per month.

We found in Table 2 that the theoretical mispricing return premium was related to firm size and book-to-market ratio. Therefore to take account of the possibility that the FF3 model does not adequately capture difference in returns attributable to differences in size and book-to-market ratio, we adopted a characteristic adjusted return approach. At each year end, 25 equally-weighted benchmark portfolios were formed by first assigning the sample firms into size quintiles based on NYSE quintile breakpoints; then within each size quintile, assigning firms to book-to-market quintiles based on the corresponding NYSE book-to-market quintile breakpoints. The characteristic adjusted stock returns are the difference between the average returns and the returns on the corresponding benchmark portfolio. The first line of Panel $\mathrm{C}$ of Table 4 reports the characteristic adjusted returns. The spread between the high and the low premium portfolios is now 48 bp per month with a $t$-statistic of 2.60. The characteristic adjusted returns were further adjusted for risk using the 3 risk models and the results are also reported in Panel C. This further adjustment of the returns does not change the results. It is not surprising to find that the return spread between the high and low premium portfolios is smaller for size and book-to-market characteristic adjusted returns, since the benchmark portfolios used to adjust returns are themselves affected by the mispricing return premium.

It has been suggested to us that our results may be due to the use of relatively high 
frequency, monthly, returns and that it would disappear if a longer period were used to compute returns. To explore this, we calculate quarterly returns on our portfolios and regress them on quarterly returns on the FF factors. ${ }^{13}$ The results, which are reported in Panel D of Table 4, basically confirm our previous findings. The FF3 $\alpha$ 's continue to increase monotonically across the return premium portfolios and the spread between the FF3 $\alpha$ 's on high and low premium portfolios is $2.45 \%$ per quarter with a t-statistic of 2.49 . Only for the momentum adjusted FF4 $\alpha^{\prime}$ is there a hint of lack of robustness. The $\alpha$ 's are no longer quite monotonic, and while the spread in $\alpha$ 's between between the high and low premium portfolios is a healthy $1.58 \%$ per quarter, the corresponding t-statistic is only 1.58. Of course, this reduction in the t-statistic is in part due to the smaller number of observations when quarterly returns are used. Although these quarterly return results are less compelling, it is important to recognize that the overwhelming majority of asset pricing tests have been conducted at the monthly frequency where our evidence of the mispricing return premium is unambiguous.

Malkiel and Xu (2006) and Spiegel and Wang (2006) have found a positive association between risk adjusted returns and idiosyncratic volatility, ${ }^{14}$ and we saw in Table 3 that the mispricing return premium is positively related to idiosyncratic volatility. This raises the possibility that our findings are due to the positive premium for idiosyncratic volatility. Therefore, in order to determine whether the mispricing return premium provides incremental explanatory power for risk adjusted returns relative to idiosyncratic volatility, securities were sorted into quintiles based on idiosyncratic volatility, then within each quintile, further sorted into 5 portfolios on the basis of $\hat{B}_{1}$. In results not reported here, the spread in risk adjusted returns between the high and low mispricing return premium portfolios was found to be positive and significant at the $10 \%$ level or better for all but the lowest idiosyncratic risk quintile - for the highest idiosyncratic risk quintile, the spread is $60 \mathrm{bp}$ per month with a t-statistic of 2.90. On the other hand, when the order of the sorts was reversed, the spread in risk adjusted return between the high and low idiosyncratic volatility portfolios was significant only for the highest mispricing return premium quintile (t-statistic of 1.89).

\footnotetext{
${ }^{13}$ The quarterly returns are calculated by compounding the monthly returns already calculated.

${ }^{14}$ Ang et al. (2006) report a negative return premium for idiosyncratic volatility. However, their study is not comparable to this or the cited studies, since their estimates of idiosyncratic volatility are derived from daily rather than monthly returns.
} 
Thus while there is strong evidence for the mispricing return premium, the evidence for an independent idiosyncratic volatility premium is weak at best.

As a final robustness check we shall examine whether other proxies for the mispricing return premium are also associated with excess risk-adjusted returns.

\subsection{Variance Ratio and Volatility of Residual Returns}

Equation (8) shows that the return premium, $B_{1}$, is increasing in the volatility of mispricing $\sigma_{z}$, and decreasing in the first order autocorrelation $\rho_{1}^{z}$. Unfortunately, as we have seen, the mispricing variable, $z$, is not directly observable and therefore these parameters can be inferred only by making strong assumptions about the stochastic process of the mispricing variable. These assumptions are unlikely to be satisfied in practice. Therefore, as a robustness check, in this section we adopt a more informal approach to proxying for the mispricing return premium.

Define the k-month variance ratio for (FF3) residual returns by $V R(k) \equiv\left(\operatorname{var}\left(e^{k}\right) / k\right) / \operatorname{var}\left(e^{1}\right)$, where $e^{k}$ is the cumulative residual return over $\mathrm{k}$ months. First, we observe that in the absence of mispricing, the FF3 residuals will be serially independent, so that $V R(k)=1$. To the extent that there is transient mispricing, the variance ratio will be less than 1 , and the stronger is the mean reversion in mispricing, the lower will the ratio. This suggests using the variance ratio of residual returns as a proxy for $\rho_{1}^{z}$. The volatility of residual returns, $\sigma_{e}$, depends on both the idiosyncratic volatility of the fundamental returns $\left(\sigma_{\epsilon}\right)$ and the variability of mispricing $\left(\sigma_{z}\right)$. Therefore we can think of residual return volatility $\left(\sigma_{e}\right)$ as a noisy signal of the volatility of mispricing $\left(\sigma_{z}\right)$. Hence we expect the mispricing return premium to decrease in the variance ratio and to increase in residual return volatility.

Our analysis is based on the 24-month variance ratio. ${ }^{15} 10$ portfolios were formed each year based on the 24-month residual variance ratio estimated over the previous 60 months, $V R(24)$. Only stocks with at least 36 monthly returns within the past 5 years were considered. The variance of the one month residual returns was estimated using the previous 5 years' FF3 residuals. The variance of the sum of 24 months' residuals, $\operatorname{var}\left(e^{24}\right)$,

\footnotetext{
${ }^{15}$ Results obtained using 12 and 36 month variance ratios were similar.
} 
was estimated as the average of the squared sum of residuals over each 24-month period in the previous 60 months. Thus, the residuals over months 1-24 were summed and squared, similarly with the residuals for months $2-25, . ., 37-60$, and the average of these was taken as the estimate of the 24-month variance. Securities were then assigned to one of 10 portfolios according to the variance ratio estimate.

The characteristics of the portfolios are reported in Panel A of Table 5. The estimates of the variance ratios for individual stocks are very noisy, so that the sample selection premium involved in sorting on this variable causes the spread of portfolio average variance ratio estimates to be very wide, ranging from 0.12 to 2.04 as compared with the value of unity implied by the iid assumption. Nevertheless, it is striking that for 8 out of the 10 portfolios the estimate of $V R(24)$ is less than unity; this, together with the fact that the average residual autocorrelation is negative for 9 portfolios, suggests a widespread tendency for residual returns to reverse themselves, which is consistent with transient mispricing. There is relatively little difference in the average residual variances of the stocks in the portfolios except for the high VR portfolio whose residual variance is about $33 \%$ higher than that of the other portfolios. Firm size tends to decrease with the variance ratio, but the variation in firm size across decile portfolios is not as marked as it was for the previous two portfolio formation methods. As conjectured, the (FF3) risk adjusted returns reported in Panel B are decreasing in the variance ratio; the correlation between the risk adjusted returns and the variance ratio is -0.89 . This pattern of returns is consistent with that reported in Table 3: low VR portfolios that we expect to have a higher return premium have higher risk adjusted returns. The (FF3) risk adjusted spread is $4.08 \%$ per year when sorting on $V R(24)$, as compared to a spread of over $8 \%$ when sorting on the Kalman filter based estimates of the return premium; however, the t-statistic on the spread is now 3.91, as compared with 3.25 reported in Table 3 .

As a robustness check on these variance ratio results, the analysis was repeated using a characteristic adjusted return approach as in Section 5.2.3. The return spread falls from 34 bp per month when adjusted for risk using the FF3 model as reported in Panel B of Table 5, to 23 bp per month using the characteristic adjusted returns, as reported in Panel B of Table 6. This reduction in the return spread when using characteristic adjusted returns 
is consistent with our previous observation that the benchmark returns are likely to be affected by the mispricing return premium. As seen in Panel C, further adjustment for risk of the characteristic adjusted returns does not change the results.

Equation (8) shows that the theoretical mispricing return premium, $B_{1}$, is the product of the variance of mispricing, $\sigma_{z}^{2}$, and $\left(1-\rho_{1}^{z}\right)$. Since the variance ratio is a proxy for $\rho_{1}^{z}$, and the residual variance of returns a proxy for $\sigma_{z}^{2}$, we should expect their effects on the mispricing return premium to be multiplicative: for low (high) residual variance, the effect of the variance ratio should be small(large); and for high (low) variance ratio, the effect of residual variance should also be small (large).

In order to determine the effect of the residual variance on the relation between risk adjusted returns and the variance ratio, 25 portfolios were formed each year. First the stocks were sorted into quintiles based on the estimated variance of the residual returns. Then within each variance quintile the stocks were further sorted into quintiles based on $V R(24) .{ }^{16}$ The time series of returns on the resulting 25 portfolios were calculated as in the previous case assuming equal investments in each stock and annual rebalancing. Riskadjusted returns were then calculated as before and the results are reported in Table 7. We focus on the results for returns that are adjusted for risk using the 3 and 4 factor models, which are quite similar.

The relation between risk adjusted returns and the variance ratio depends strongly on the residual variance, as expected. As the residual variance increases, the relation, which is negative and insignificant for the lowest residual variance quintile, becomes positive and is highly significant for the two highest residual variance quintiles. The spread in the risk adjusted returns for the highest residual variance quintile is $9.12 \%$ per year with a t-statistic of 4.51 .

In order to determine the effect of the variance ratio on the relation between the residual variance and risk adjusted returns, 25 portfolios were reformed by sorting first on the variance ratio and then on the residual variance. The results are reported in Table 8. As we conjectured, only for the lower VR quintiles is there any evidence that residual variance

\footnotetext{
${ }^{16}$ Similar results were obtained when sorting simultaneously on these two variables.
} 
is associated with risk adjusted returns after controlling for VR. For the lowest VR quintile the (FF3) risk adjusted return increases monotonically in the residual variance, and the spread between the risk-adjusted returns on the high and low $\sigma_{e}^{2}$ portfolios is $9.36 \%$ per year which is significant at $1 \%$ level. ${ }^{17}$

In summary, risk adjusted returns are increasing in residual variance, but only when the variance ratio is low; and risk adjusted returns are decreasing in the variance ratio, but only when the residual variance is high.

\section{Conclusion}

In this paper we have shown that when market prices differ from fundamental prices because of stochastic pricing errors which are zero on average, a premium in average returns is created as a result of Jensen's inequality which we have called the theoretical mispricing return premium, $B_{1}$ : this is decreasing in the persistence of the pricing errors and increasing in their volatility. A second premium is created by the covariance of the fundamental return with the innovation in the proportional mispricing, and there is a third premium due to the effect of average mispricing on the dividend yield. Additional return effects are created if the mispricing is time-dependent. In this paper we have concentrated on the pure Jensen's inequality effect, $B_{1}$, forming portfolios based on estimates of $B_{1}$, and testing whether riskadjusted returns reflect this variable or whether its effect is offset by the other premia and effects we have mentioned. We find strong evidence that risk-adjusted returns are affected in the direction predicted by $B_{1}$.

In order to estimate $B_{1}$ we assume that fundamental returns follow the Fama-French three-factor model, and estimate the log of mispricing, $z_{i, t}$, by applying a Kalman filter to the residuals from a regression of stock returns on the Fama-French factors under the assumption that mispricing follows an $\mathrm{AR}(1)$ process whose innovations are orthogonal to fundamentals. We confirm that the $z_{i, t}$ estimates correspond to mispricing by showing that they predict future risk-adjusted returns; we find that they have incremental explanatory

\footnotetext{
${ }^{17}$ While Malkiel and Xu (2006), Spiegel and Wang (2006), and Ang et al. (2006a,b) find significant associations between risk adjusted returns and idiosyncratic volatility, none of them consider the variance ratio.
} 
power relative to the lagged return. The theoretical mispricing premium, $B_{1}$, depends only on the parameters of the $\operatorname{AR}(1)$ process of the pricing errors. We find that the premium is larger for small, low price, growth firms with high share turnover and dispersion in analyst earnings estimates; it seems reasonable that such firms should be most subject to pricing errors. Each year we form ten equally weighted portfolios on the basis of $B_{1}$ estimates derived from data over the previous five years. For the high premium portfolio the average volatility of mispricing, $\sigma_{z}$, is approximately $17 \%$ as compared with $1 \%$ for the low premium portfolio. The average estimated autocorrelation of mispricing is 0.32 for the high premium portfolio. This is inconsistent with the mispricing we find being simple iid bid-ask bounce. However, it falls within the range of dealer inventory and price adjustment parameters found by Madhavan and Smidt (1993).

The returns on the 10 portfolios are linked over time assuming no rebalancing except at year end. When the returns are regressed on the the three Fama-French (1993) factors, the intercepts or risk adjusted returns have a correlation of 0.96 with the estimated mispricing return premium, and the annualized spread in the risk adjusted returns between the highest and lowest premium portfolios is $8.64 \%$ with $t$-statistic of 3.25 . When returns are adjusted for risk by subtracting the returns on size and book-to-market portfolios, the annualized return spread is $5.76 \%$ per year with $t$-statistic of 2.60 . Thus there is significant evidence that risk(characteristic) adjusted returns are affected by the mispricing return premium that we have analyzed. The results are also robust to winsorization, lagging the data used to form the portfolios and to the use of quarterly rather than monthly returns.

As a further robustness check, we also form portfolios based on the 24-month variance ratio of the residuals from the Fama-French 3-factor model. Consistent with our hypothesis, we find that risk-adjusted and characteristic adjusted returns are significantly higher on low variance ratio portfolios, and when we sort first on residual return volatility and then on variance ratio we find that the effect is more pronounced for the high residual volatility groups of portfolios. Moreover, when we form portfolios first on the variance ratio and then on residual volatility, we find that the relation between risk adjusted returns and the residual variance is the strongest for the low variance ratio quintiles. These findings are consistent with the hypothesis that the variance ratio of residual returns is a good proxy 
for the first order autocorrelation of mispricing and that the volatility of residual returns is a proxy for the volatility of mispricing.

We have provided strong empirical evidence for the effect of the mispricing return premium on the cross-section of security returns. This has implications for the conduct and interpretation of empirical tests of the effects on risk-adjusted returns of variables such as liquidity and idiosyncratic volatility. Such variables are likely to proxy also for the mispricing return premium, so that the return spreads that are found by sorting on these variables may be due in part to the mispricing return premium that we have identified. 


\section{Appendix: Kalman Filter Algorithm for an AR1 z process}

Assume that the logarithm of the mispricing component, $z_{t}$, follows a AR1 process, the transition equation can then be denoted as

$$
\alpha_{t}=T_{t} \alpha_{t-1}+w_{t} \text { with } w_{t} \sim N\left(0, Q_{t}\right)
$$

where $\alpha_{t}=\left[z_{t}\right], T_{t}=\left[\phi_{1}\right], w_{t}=\left[\eta_{t}\right], Q_{t}=\left[\sigma_{\eta}^{2}\right]$.

The observation equation is based on the FF3 risk adjusted returns, $e_{t}, t=1,2, \ldots T$, and is given

$$
e_{t}=\mu+s_{t}^{\prime} \alpha_{t}+\epsilon_{t}
$$

with $s_{t}=\left[\begin{array}{l}1 \\ -1\end{array}\right]$, and $\epsilon_{t} \sim N\left(0, \sigma_{\epsilon}^{2}\right)$

At the end of each year from 1967 to 2003, for each stock, a Kalman filter is fitted to the FF3 adjusted returns over the past 60 months, following a 2-stage iteration process. The first stage is the prediction stage. At time $t-1$, the optimal predictor, $\alpha_{t \mid t-1}$, and the associated covariance, $P_{t \mid t-1}$, are given by

$$
\begin{aligned}
\alpha_{t \mid t-1} & =T_{t} \alpha_{t-1 \mid t-1} \\
P_{t \mid t-1} & =T_{t} P_{t \mid t-1} T_{t}^{\prime}+Q_{t}
\end{aligned}
$$

The second stage is the updating stage. When $e_{t}$ becomes observable at time $t$, we can calculate the prediction errors given by the predicted parameter in the first stage, $v_{t}=e_{r}-e_{t \mid t-1}=s_{t}^{\prime}\left(\alpha_{t}-\alpha_{t \mid t-1}\right)+\epsilon_{t}$, with mean of 0 , and variance of $s^{\prime} P_{t \mid t-1} s_{t}+\sigma_{\epsilon}^{2}$. Define, $f_{t} \equiv s_{t}^{\prime} P_{t \mid t-1} s_{t}+\sigma_{\epsilon}^{2}$, the parameters then are updated as follows:

$$
\begin{aligned}
& \alpha_{t \mid t}=\alpha_{t \mid t-1}+P_{t \mid t-1} s_{t}\left(e_{t}-s_{t}^{\prime} \alpha_{t \mid t-1}\right) f_{t}^{-1} \\
& P_{t \mid t}=P_{t \mid t-1}-P_{t \mid t-1} s_{t} s_{t}^{\prime} P_{t \mid t-1} f_{t}^{-1}
\end{aligned}
$$

and $P_{t \mid t-1} s_{t} f_{t}^{-1}$ is also known as "Kalman Gain". The log likelihood function of the observations $\left(e_{1}, e_{2}, \ldots e_{t}\right)$ can be calculated as

$$
L=-\frac{T}{2} \log (2 \pi)-\frac{1}{2} \sum_{t=1}^{T} \log \left(f_{t}\right)-\frac{1}{2} \sum_{t-1}^{T} \frac{v_{t}^{2}}{f_{t}}
$$


Following Campbell (1989), initial guesses of $\alpha_{0}$ and $P_{0}$ are set to zero and $\frac{\sigma_{\eta}^{2}}{1-\phi_{1}^{2}}$, respectively. We maximize the above log likelihood function to get the final parameter estimates. Based on the estimated parameters, the premium is calculated by

$$
\hat{B}_{1}=e^{\left(1-\hat{\phi}_{1}\right) \hat{\sigma}_{z}^{2}}-1=e^{\frac{\hat{\sigma}_{\eta}^{2}}{1+\hat{\phi}_{1}}}-1
$$




\section{Reference}

Acharya, V.V., and L.H. Pedersen, 2005, Asset Pricing with Liquidity Risk, Journal of Financial Economics, 77, 375-410.

Amihud, Y., 2002, Illiquidity and Stock Returns: Cross-section and Time-series Effects, Journal of Financial Markets, 5, 31-56.

Amihud, Y., and H. Mendelson, 1986, Asset Pricing and the Bid-ask Spread, Journal of Financial Economics, 17, 223-249.

Amihud, Y., and H. Mendelson, 1987, Trading Mechanisms and Stock Returns: An Empirical Investigation, The Journal of Finance, 42, 533-553.

Amihud, Y., Mendelson, H., and L. H. Pedersen, 2005, Liquidity and Asset Prices, Foundations and Trends in Finance, 1, 269-364

Ang, A., R., Hodrick, Y. Xing, and X. Zhang, 2006 a, The Cross-Section of Volatility and Expected Returns, The Journal of Finance, 61, 259-299.

Ang, A., R., Hodrick, Y. Xing, and X. Zhang, 2006 b, High Idiosyncratic Volatility and Low Returns: International and Further U.S. Evidence, Working Paper, Columbia University.

Arnott, R., J. Hsu, J. Liu, and H. Markowitz, 2006, Does Noise Create the Size and Value Factors? Research Affiliates Working Paper.

Atkins, A., and E. Dyl, 1997, Market structure and reported trading volume: Nasdaq versus the NYSE, Journal of Financial Research, 20, 291-304.

Baker, M., and J. Wurgler 2006, Investor Sentiment and the Cross Section of Stock Returns, The Journal of Finance61, 1645-1680.

Bernard, V., J. Thomas, and J. Wahlen, 1997, Accounting Based Stock Price Anomalies: Separating Market Inefficiencies form Research Design Flaws. Contemporary Accounting Research, 14, 89-136.

Bessembinder, H., and I. Kalcheva, 2006, Liquidity Biases in Asset Pricing Tests, University of Utah Working Paper.

Blume, M., and R. F. Stambaugh, 1983, Biases in Computed Returns: an Application to the Size Effect, Journal of Financial Economics, 12, 387-404.

Brennan, M.J., Jegadeesh, N. and B. Swaminathan, 1993, Investment Analysis and the Adjustment of Stock Prices to Common Information, Review of Financial Studies, 6, 799-824.

Campbell, A. 1989. Forecasting, Structural Time Series Models and the Kalman Filter. 
Cambridge University Press.

Campbell, J.Y., and A.S. Kyle, Smart Money, Noise Trading and Stock Price Behavior, Review of Economic Studies, 60, 1-34.

Canina, L., R. Michaely, R. Thaler and K. Womack, 1998, Caveat Compounder: a Warning about Using the Daily CRSP Equal-weighted Index to Compute Long-run Excess Returns, The Journal of Finance, 53, 403-416.

Carhart,M. 1997. On Persistence in Mutual Fund Performance, The Journal of Finance, 52. $57-82$.

Chordia, T., R.Roll, and A. Subrahmanyam, 2000, Commonality in Liquidity, Journal of Financial Economics, 56, 3-28.

Cochrane, J. H. 1988. How Big is the Random Walk in GNP?, Journal of Political Economy, 96, 893-920.

Cox, J.C., J. Ingersoll, and S.A. Ross, 1981, A Re-Examination of Traditional Hypotheses about the Term Structure of Interest Rates, The Journal of Finance, 36, 769-799 .

Daniel, K., D. Hirshleifer, and A. Subrahmanyam, 1998, Investor Psychology ad Security Market Under- and Over-Reactions, The Journal of Finance, 53, 1839-1886.

de Bondt, W., and R. Thaler, 1985, Does the Stock Market Overreact?, The Journal of Finance, 40, 793-805.

de Bondt, W., and R. Thaler, 1987, Further Evidence of Investor Overreaction and Stock Market Seasonality, The Journal of Finance, 42, 557-582.

DeLong, J., A. Shleifer, L. Summers, and R. Waldmann, 1990, Noise Trader Risk in Financial Markets, Journal of Political Economy, 98, 703-738.

Fama, E., 1991, Efficient Capital markets II, The Journal of Finance, 46, 1575-1618.

Fama, E.F., and K.R. French, 1993, Common Risk Factors in the Returns on Bonds and Stocks, Journal of Financial Economics, 33, 3-56.

French, K. R., and R. Roll, 1986. Stock Return Variances, Journal of Financial Economics, 17. 5-26.

Gemmill, G., and J.C. Thomas, 2002, Noise Trading, Costly Arbitrage and Asset Prices: Evidence from Closed End Funds, The Journal of Finance, 57, 2571-2594.

Harvey, A. 1981. Time Series Models John Wiley \& Sons, New York.

Hendershott, T., and Seasholes, M., 2007. Market Maker Inventories and Stock Prices, American Economic Review, 97, 210-214.

Hong, H., T. Lim, and J.C. Stein, 2000, Bad News Travels Slowly: Size, Analyst Cov- 
erage and the Profitability of Momentum Strategies, The Journal of Finance,55, 265-295.

Hou, K., and T.J. Moskowitz, 2005, Market Frictions, Price Delay, and the Cross-section of Expected Returns, Review of Financial Studies, 18, 981-1020.

Huang, M., 2003, Liquidity Shocks and Equilibrium Liquidity Premia, Journal of Economic Theory, 109, 104-121.

Jegadeesh, N., 1990, Evidence of Predictable Behaviors of Security Return, The Journal of Finance, 45, 881-898.

Jegadeesh N., and S. Titman, 1993, Returns to Buying Winners and Selling Losers: Implications for Stock Market Efficiency, The Journal of Finance, 48, 65-91.

Jegadeesh N., and S. Titman, 1995, Overreaction, Delayed Reaction, and Contrarian Profits, Review of Financial Studies, 8, 973-993.

Jackson, A., and T. C. Johnson, 2006, Unifying Underreaction Anomalies, Journal of Business, 79, 75-114.

Khil, J, and B. Lee, 2002, A Time-Series Model of Stock Returns with a Positive ShortTerm Correlation and a Negative Long-Term Correlation, Review of Quantitative Finance and Accounting, 18, 381-404.

Korajczyk, R.A., and R. Sadka, 2004, Are Momentum Profits Robust to Trading Costs?, The Journal of Finance, 59, 1039-1082.

Kumar, A., and C.M.C. Lee, 2006, Retail Investor Sentiment and Return Comovement, The Journal of Finance, 61, 2451-2486.

Kyle, A., 1985, Continuous Auctions and Insider Trading, Econometrica, 53, 1315-1336.

Lee, C., Shleifer, A., and R. Thaler, 1991, Investor sentiment and the Closed End Fund Puzzle, The Journal of Finance, 46, 75-110.

Lee, C., and B. Swaminathan, 2000, Price Momentum and Trading Volume, The Journal of Finance, 55, 2017-2069.

Liu, W., 2006, A Liquidity Augmented Capital Asset Pricing Model, Journal of Financial Economics, forthcoming.

Liu, W., and N. Strong, 2006, Biases in Decomposing Holding Period Returns, Review of Financial Studies, forthcoming.

Lo, A.W., Mamaysky, H., and J. Wang, 2001, Asset Prices and Trading Volume under Fixed Transaction Costs, NBER Working Paper.

Madhavan, A., and S. Smidt, 1993, An Analysis of Changes in Specialist Inventories and Quotations, The Journal of Finance, 48, 1995-1628. 
Malkiel, B, and Xu, Y., 2006, Idiosyncratic Risk and Security Returns, University of Texas, Dallas Working Paper.

Miller, E., 1977, Risk, Uncertainty and Divergence of Opinion, The Journal of Finance, $32,1151-1168$.

Mohanram, P.S., 2004, Separating Winners from Losers among low book-to-market stocks using financial statement analysis, working paper available at SSRN: http://ssrn.com/abstract=4031

Pastor, L. and R. F. Stambaugh, 2003, Liquidity Risk and Expected Stock Returns, Journal of Political Economy, 111, 642-685.

Pastor, L. and Veronesi, P., 2003, Stock Valuation and Learning about Proftiability, The Journal of Finance, 58, 1749-1789.

Poterba, J., and L. Summers, 1988, Mean Reversion in Stock Prices, Journal of Financial Economics, 22, 27-59.

Roll, R., 1983, On Computing Mean Returns and the Small Firm Premium, Journal of Financial Economics, 12, 371-386.

Sadka, R., 2006, Momentum and Post-earnings Announcement Drift Anomalies: the Role of Liquidity Risk, Journal of Financial Economics, 80, 309-350.

Siegel, J. J., 1972, Risk, interest rates, and the forward exchange, Quarterly Journal of Economics, 86, 303-309.

Sloan, R., 1996, Do stock prices fully reflect the information in accruals and cash flows about future earnings?, Accounting Review, 71, 289-315.

Spiegel, M., and X. Wang, 2005, Cross-Sectional Variation in Stock Returns: Liquidity and Idiosyncratic Risk, Working Paper, Yale University.

Swaminathan B., 1996, Time-varying Expected Small Firm Returns and Closed-end Fund Discounts. Review of Financial Studies, 9, 845-888.

Watson, M. 1986. Univariate Detrending Methods with Stochastic Trends. Journal of Monetary Economics. 18: 49-75. 
Table 1: Returns on Equally-Weighted Decile Portfolios formed each month $t$, from January 1967 to December 2004, on Kalman Filter Estimates of the logarithm of mispricing, $z_{t-1} z$, the logarithm of mispricing, is estimated each month from the Fama-French 3-factor model residuals estimated over the previous 60 months. The estimation uses a Kalman filter and assumes an AR(1) process for $z$. Securities are allocated to portfolios on the basis of the $z$ estimates for the previous month. Equally weighted excess returns on the portfolios are then regressed on the 3 Fama-French factors. The intercept, $\alpha$, from these regressions is reported in Panel A. Panel B reports returns on portfolios formed each month by sorting on $R_{t-1}$, the previous month return, and then on $z_{t-1}$. The returns and $\alpha$ 's are in per cent per month, and the $t$-statistics are adjusted for autocorrelation and heteroscedasticity.

Panel A: Portfolios formed on $z_{t-1}$

\begin{tabular}{|c|c|c|c|c|c|c|c|c|c|c|c|}
\hline & $\begin{array}{l}\text { Portfolio } \\
\text { Low } z_{t-1}\end{array}$ & 2 & 3 & 4 & 5 & 6 & 7 & 8 & 9 & $\begin{array}{l}\text { Portfolio } \\
\text { High } z_{t-1}\end{array}$ & $\begin{array}{c}\text { Spread } \\
\text { High-Low }\end{array}$ \\
\hline Average $z_{t-1}$ & -6.37 & -2.03 & -1.04 & -0.51 & -0.17 & 0.07 & 0.38 & 0.92 & 2.02 & 7.44 & \\
\hline Average Return & 2.24 & 1.89 & 1.72 & 1.63 & 1.43 & 1.19 & 0.87 & 0.85 & 0.72 & 0.57 & -1.67 \\
\hline t-statistic & 7.16 & 6.82 & 6.57 & 6.55 & 5.96 & 4.96 & 3.60 & 3.37 & 2.86 & 1.98 & -10.17 \\
\hline FF3 $\alpha$ & 0.87 & 0.55 & 0.39 & 0.35 & 0.19 & -0.04 & -0.35 & -0.42 & -0.52 & -0.67 & -1.54 \\
\hline t-statistic & 8.22 & 6.36 & 5.11 & 5.44 & 3.11 & -0.63 & -5.53 & -6.99 & -7.58 & -5.68 & -8.94 \\
\hline
\end{tabular}

Panel B: Portfolios formed first on $R_{t-1}$, then on $z_{t-1}$

\begin{tabular}{|c|c|c|c|c|c|c|c|c|c|c|c|c|}
\hline \multirow[b]{3}{*}{ High $R_{t-1}$} & \multicolumn{6}{|c|}{ FF3 $\alpha(\%)$} & \multicolumn{6}{|c|}{ t-statistic } \\
\hline & Low & & & & High & Spread & Low & & & & High & Spread \\
\hline & -0.61 & -0.44 & -0.59 & -0.79 & -1.08 & -0.47 & -4.86 & -4.78 & -6.39 & -5.56 & -6.51 & -3.18 \\
\hline 2 & 0.09 & 0.05 & -0.19 & -0.33 & -0.35 & -0.45 & 1.00 & 0.57 & -2.22 & -4.27 & -4.29 & -3.82 \\
\hline 3 & 0.38 & 0.33 & 0.24 & -0.23 & -0.35 & -0.73 & 4.27 & 3.87 & 2.87 & -2.32 & -3.48 & -6.35 \\
\hline Low $R_{t-1}$ & 1.36 & 1.01 & 0.62 & 0.44 & 0.14 & -1.21 & 9.16 & 7.45 & 5.24 & 3.13 & 1.13 & -9.62 \\
\hline
\end{tabular}


Table 2: Mispricing Return premium and Firm Characteristics

The reported coefficients are time series averages of coefficients from cross-sectional regressions of security mispricing return premium estimates on firm characteristics.

The AR1 coefficient, $\hat{\phi_{1}}$, the variance of mispricing, $\hat{\sigma_{z}^{2}}$ and the theoretical mispricing return premium, $\hat{B_{1}}$, are estimated from the residuals from Fama-French 3-factor regressions using a Kalman filter and assuming an AR1 process for mispricing. Only firms with at least 2 analysts are included in the regressions. Size is the market value of equity at the end of the year. $B / M$ is the book-to-market ratio calculated from the year end market value and the most recent book equity that is available at least two quarters before the year end. Price is the share price at the end of the year. Turnover is the ratio of the average number of shares traded per month to the number of shares outstanding during the last quarter of the year. NASDAQ turnover is multiplied by 0.6. \#Analysts is the number of investment analysts following the firm at the end of the year. DISP is the dispersion of analysts' earnings forecasts for the next 1-2 quarters.

$t$-statistics are computed using standard errors computed from the time series of the coefficients and take account of heteroscedasticity and autocorrelation using a Newey-West adjustment with 4 lags.

\begin{tabular}{|c|c|c|c|c|c|c|}
\hline \multirow{3}{*}{ 1976-2003 } & \multicolumn{2}{|c|}{$\hat{\phi}_{1}(\%)$} & \multicolumn{2}{|c|}{$\hat{\sigma_{z}^{2}}$} & \multicolumn{2}{|c|}{$\hat{B_{1}}$} \\
\hline & coeff & t-stat & coeff & t-stat & coeff & t-stat \\
\hline & & & & & & \\
\hline Const & -0.85 & -0.57 & 85.76 & 4.66 & 6.15 & 4.97 \\
\hline $\log ($ Size $)$ & 0.75 & 2.20 & -8.52 & -3.67 & -0.65 & -4.07 \\
\hline $\mathrm{B} / \mathrm{M}$ & 1.74 & 3.20 & -5.10 & -3.24 & -0.36 & -3.92 \\
\hline Price & 0.04 & 2.02 & -0.09 & -3.18 & -0.01 & -4.86 \\
\hline Turnover & -0.35 & -4.32 & 2.14 & 5.70 & 0.12 & 4.44 \\
\hline $\log$ (\#Analysts) & 1.83 & 2.70 & -1.18 & -0.64 & -0.04 & -0.29 \\
\hline DISP & 0.19 & 0.12 & 9.59 & 1.88 & 0.45 & 2.07 \\
\hline $\operatorname{Adj}^{2}(\%)$ & 0.88 & & 5.68 & & 14.25 & \\
\hline
\end{tabular}


Table 3: Properties of Equally-Weighted Decile Portfolios formed each year from January 1967 to December 2004 on Kalman Filter Estimates of the Mispricing Return Premium

Mispricing Return premium (MRP), which is annualized and in per cent, is equal to $\left(1-\phi_{1}\right) \sigma_{z}^{2}$, where $\phi_{1}$ and $\sigma_{z}$ are the first order autocorrelation and volatility of mispricing which are estimated from Fama-French 3-factor residuals using a Kalman filter and assuming an $\mathrm{AR}(1)$ process for mispricing. The $\beta^{\prime} s$ are the loadings of the portfolio returns on the 3 Fama-French and the Carhart Momentum factors. Size is the time series mean portfolio size in billion $\$ . \sigma_{z}$ and $\sigma_{\epsilon}$, the volatility of the $(\log )$ mispricing variable $(z)$ and the monthly volatility of the fundamental return $(\epsilon)$, are quoted in per cent. $\sigma_{e}$ is the average volatility of residuals of Fama-French 3-factor regression over the previous 60 month, quote in \%. Panel B reports Average returns and the intercepts $(\alpha)$ from regressions of excess returns on the market excess returns (CAPM), the 3 Fama-French factors (FF3), and the 3 Fama-French factors plus the Carhart Momentum factor (FF4). The returns and $\alpha^{\prime} s$ are in per cent per month, and the $t$-statistics are adjusted for autocorrelation and heteroscedasticity. Stocks for which the Kalman filter fails to converge are included in Portfolio NCV.

\begin{tabular}{|c|c|c|c|c|c|c|c|c|c|c|c|c|}
\hline & $\begin{array}{c}\text { Port. } \\
\text { Low MRP }\end{array}$ & 2 & 3 & 4 & 5 & 6 & 7 & 8 & 9 & $\begin{array}{c}\text { Port. } \\
\text { High MRP }\end{array}$ & & $\begin{array}{l}\text { Port. } \\
\text { NCV }\end{array}$ \\
\hline \multicolumn{13}{|c|}{ Panel A: Portfolio Characteristics } \\
\hline$\beta_{m k t}$ & 0.90 & 0.93 & 0.93 & 0.98 & 1.02 & 1.04 & 1.01 & 1.06 & 1.03 & 1.03 & & 1.01 \\
\hline t-statistic & 43.15 & 45.44 & 44.27 & 45.70 & 46.91 & 44.29 & 38.14 & 38.49 & 31.23 & 20.54 & & 53.83 \\
\hline$\beta_{S M B}$ & 0.46 & 0.48 & 0.55 & 0.59 & 0.69 & 0.76 & 0.91 & 1.14 & 1.38 & 1.66 & & 0.84 \\
\hline t-statistic & 14.54 & 14.93 & 15.09 & 12.53 & 17.36 & 14.48 & 20.08 & 23.18 & 26.91 & 18.52 & & 23.78 \\
\hline$\beta_{H M L}$ & 0.43 & 0.40 & 0.39 & 0.40 & 0.40 & 0.40 & 0.31 & 0.34 & 0.25 & 0.18 & & 0.25 \\
\hline t-statistic & 10.63 & 11.19 & 8.69 & 9.45 & 9.29 & 8.46 & 6.46 & 5.11 & 3.53 & 1.30 & & 8.21 \\
\hline$\beta_{M O M}$ & -0.03 & -0.03 & -0.04 & -0.04 & 0.01 & -0.04 & -0.01 & -0.03 & -0.04 & -0.06 & & -0.07 \\
\hline t-statistic & -1.04 & -1.12 & -1.15 & -1.29 & 0.19 & -1.17 & -0.27 & -0.77 & -0.77 & -0.48 & & -1.77 \\
\hline Size $(\$ B)$ & 2.13 & 2.05 & 1.61 & 1.30 & 1.02 & 0.82 & 0.52 & 0.31 & 0.17 & 0.09 & & 1.01 \\
\hline$\phi_{1}$ & -0.13 & -0.11 & -0.06 & -0.01 & 0.05 & 0.09 & 0.13 & 0.16 & 0.21 & 0.32 & & \\
\hline$\sigma_{z}(\%)$ & 1.08 & 1.91 & 2.59 & 3.28 & 4.05 & 4.84 & 5.86 & 7.12 & 9.25 & 16.70 & & \\
\hline$\sigma_{\epsilon}(\%)$ & 7.79 & 7.66 & 7.85 & 8.07 & 8.29 & 8.54 & 9.11 & 10.01 & 10.88 & 13.09 & & \\
\hline$\sigma_{e}(\%)$ & 7.94 & 8.09 & 8.56 & 9.08 & 9.63 & 10.27 & 11.30 & 12.80 & 14.73 & 20.71 & & \\
\hline MRP (\% p.a.) & 0.14 & 0.41 & 0.71 & 1.05 & 1.46 & 1.98 & 2.72 & 3.89 & 6.07 & 16.34 & & \\
\hline \multicolumn{13}{|l|}{ Number of Stocks } \\
\hline Mean & 200 & 200 & 200 & 199 & 199 & 198 & 198 & 197 & 196 & 196 & & \\
\hline \multirow[t]{2}{*}{ Mininum } & 114 & 115 & 116 & 116 & 111 & 114 & 113 & 111 & 114 & 111 & & \\
\hline & $\begin{array}{c}\text { Port. } \\
\text { Low MRP }\end{array}$ & 2 & 3 & 4 & 5 & 6 & 7 & 8 & 9 & $\begin{array}{c}\text { Port. } \\
\text { High MRP }\end{array}$ & $\begin{array}{c}\text { Spread } \\
10-1 \\
\end{array}$ & $\begin{array}{l}\text { Port. } \\
\text { NCV }\end{array}$ \\
\hline \multicolumn{13}{|c|}{ Panel B: Returns ( per cent per month) } \\
\hline Average Return & 1.29 & 1.33 & 1.40 & 1.47 & 1.56 & 1.47 & 1.66 & 1.65 & 1.79 & 2.28 & 0.99 & 1.43 \\
\hline t-statistic & 5.58 & 5.77 & 5.71 & 5.65 & 5.55 & 5.14 & 5.39 & 4.81 & 4.62 & 5.04 & 3.24 & 4.67 \\
\hline Capm $\alpha$ & 0.38 & 0.40 & 0.46 & 0.50 & 0.56 & 0.45 & 0.63 & 0.58 & 0.70 & 1.14 & 0.77 & 0.40 \\
\hline t-statistic & 2.84 & 3.22 & 3.34 & 3.61 & 3.78 & 3.01 & 3.68 & 2.87 & 2.95 & 3.66 & 2.82 & 2.46 \\
\hline FF3 $\alpha$ & 0.06 & 0.09 & 0.15 & 0.18 & 0.23 & 0.10 & 0.31 & 0.21 & 0.34 & 0.78 & 0.72 & 0.12 \\
\hline t-statistic & 0.76 & 1.38 & 1.89 & 2.52 & 3.39 & 1.58 & 4.37 & 2.13 & 3.17 & 3.74 & 3.25 & 1.63 \\
\hline $\mathrm{FF} 4 \alpha$ & 0.09 & 0.12 & 0.18 & 0.22 & 0.22 & 0.14 & 0.32 & 0.24 & 0.38 & 0.84 & 0.75 & 0.19 \\
\hline t-statistic & 1.27 & 2.00 & 2.60 & 3.11 & 3.21 & 2.14 & 4.01 & 2.22 & 2.92 & 3.32 & 2.97 & 2.06 \\
\hline
\end{tabular}


Table 4: Robustness Tests for Portfolio Sorting Based on Kalman Filter Estimates of the Mispricing Return Premium, $B_{1}$ Four robustness tests on average, risk adjusted, and size and B/M adjusted returns for the chosen portfolios and the spread between the high and low mispricing premium portfolios. Under $10 \%$ Winsorization, stocks with the highest $10 \%$ of mispricing premium estimates are filtered out. Under $1-$ Month Lag, portfolios are constructed annually on Kalman filter estimated mispricing premium with 1-month lag. Under Size and B/M Adjusted, the average returns and risk adjusted $\alpha$ 's are based on size and book-to-market adjusted returns. Under Quarterly Returns returns and $\alpha$ 's are computed using quarterly returns on the portfolios and risk factors. Except for Quarterly Returns the returns and $\alpha^{\prime} s$ are in per cent per month, and the $t$-statistics are adjusted for autocorrelation and heteroscedasticity.

\begin{tabular}{|c|c|c|c|c|c|c|}
\hline & $\begin{array}{c}\text { Portfolio } \\
\text { Low premium } \\
\end{array}$ & 2 & 5 & 9 & $\begin{array}{c}\text { Portfolio } \\
\text { High premium } \\
\end{array}$ & $\begin{array}{c}\text { Spread } \\
10-1 \\
\end{array}$ \\
\hline \multicolumn{7}{|c|}{ Panel A: 10\% Winsorization: 1967.01-2004.12 } \\
\hline Average Return & 1.29 & 1.29 & 1.49 & 1.69 & 1.79 & 0.50 \\
\hline t-statistic & 5.59 & 5.53 & 5.50 & 4.88 & 4.57 & 2.26 \\
\hline Capm $\alpha$ & 0.37 & 0.36 & 0.51 & 0.61 & 0.69 & 0.32 \\
\hline t-statistic & 2.81 & 2.95 & 3.38 & 2.98 & 2.88 & 1.69 \\
\hline FF3 $\alpha$ & 0.05 & 0.06 & 0.15 & 0.24 & 0.33 & 0.28 \\
\hline t-statistic & 0.66 & 0.90 & 2.03 & 2.40 & 3.06 & 2.17 \\
\hline FF $4 \alpha$ & 0.08 & 0.09 & 0.19 & 0.28 & 0.37 & 0.29 \\
\hline t-statistic & 1.09 & 1.58 & 2.56 & 2.48 & 2.77 & 2.11 \\
\hline \multicolumn{7}{|c|}{ Panel B: 1-Month Lag: 1967.01-2004.12 } \\
\hline Average Return & 1.34 & 1.32 & 1.57 & 1.93 & 2.51 & 1.17 \\
\hline t-statistic & 5.61 & 5.48 & 5.98 & 5.22 & 5.45 & 4.03 \\
\hline Capm $\alpha$ & 0.40 & 0.38 & 0.59 & 0.84 & 1.38 & 0.98 \\
\hline t-statistic & 3.25 & 3.14 & 4.18 & 3.71 & 4.29 & 3.71 \\
\hline FF3 $\alpha$ & 0.12 & 0.08 & 0.27 & 0.48 & 0.98 & 0.86 \\
\hline t-statistic & 1.79 & 1.23 & 3.75 & 4.36 & 4.57 & 4.19 \\
\hline FF4 $\alpha$ & 0.13 & 0.13 & 0.32 & 0.57 & 1.10 & 0.98 \\
\hline t-statistic & 1.79 & 2.18 & 3.80 & 3.88 & 3.95 & 3.78 \\
\hline \multicolumn{7}{|c|}{ Panel C: Size and B/M Matched: 1969.01-2004.12 } \\
\hline Average Return & -0.18 & -0.26 & -0.13 & -0.13 & 0.30 & 0.48 \\
\hline t-statistic & -2.92 & -4.44 & -2.65 & -1.91 & 1.93 & 2.60 \\
\hline Capm $\alpha$ & -0.14 & -0.22 & -0.11 & -0.16 & 0.22 & 0.37 \\
\hline t-statistic & -2.39 & -4.21 & -2.41 & -2.41 & 1.51 & 2.10 \\
\hline FF3 $\alpha$ & -0.12 & -0.23 & -0.09 & -0.08 & 0.31 & 0.43 \\
\hline t-statistic & -1.98 & -4.64 & -1.82 & -1.26 & 2.11 & 2.57 \\
\hline FF4 $\alpha$ & -0.23 & -0.29 & -0.17 & -0.14 & 0.25 & 0.48 \\
\hline t-statistic & -3.86 & -5.59 & -3.23 & -2.17 & 1.58 & 2.51 \\
\hline \multicolumn{7}{|c|}{ Panel D: Quarterly Returns: 1969:I-2004:IV. (\% per quarter) } \\
\hline Average Return & 4.03 & 4.14 & 5.02 & 5.84 & 7.45 & 3.42 \\
\hline t-statistic & 5.79 & 6.09 & 5.80 & 4.74 & 5.08 & 3.22 \\
\hline Capm $\alpha$ & 1.14 & 1.19 & 1.77 & 2.11 & 3.53 & 2.39 \\
\hline t-statistic & 2.12 & 2.42 & 2.91 & 2.39 & 3.09 & 2.60 \\
\hline FF3 $\alpha$ & 0.22 & 0.29 & 0.77 & 1.18 & 2.67 & 2.45 \\
\hline t-statistic & 0.78 & 1.34 & 3.02 & 2.69 & 2.90 & 2.49 \\
\hline FF $4 \alpha$ & 0.24 & 0.20 & 0.33 & 0.63 & 1.82 & 1.58 \\
\hline t-statistic & 1.05 & 1.13 & 1.45 & 1.53 & 1.73 & 1.51 \\
\hline
\end{tabular}


Table 5: Properties of Equally-Weighted Decile Portfolios formed each year from January 1967 to December 2004 on the Variance Ratio of Residual Returns

The 24 month variance ratio is estimated each year from the residuals from Fama-French 3-factor model regressions estimated over the previous 60 months. The portfolio returns run from January 1967 to December 2004.

$V R(24)$ is the average of the 24-month variance ratios which are estimated from Fama-French 3-factor residuals over the previous 60 months The $\beta^{\prime} s$ are the loadings of the portfolio returns on the 3 Fama-French and the Carhart Momentum factors. Size is the time series mean firm size. $\sigma_{e}^{2}$ is the average variance of the residuals from FamaFrench 3-factor regressions over the previous 60 months. Panel B reports Average returns and the intercepts $(\alpha)$ from regressions of excess returns on the market excess returns (CAPM), the 3 Fama-French factors (FF3), and the 3 Fama-French factors plus the Carhart Momentum factor (FF4). The $t$-statistics are adjusted for autocorrelation and heteroscedasticity.

\begin{tabular}{|c|c|c|c|c|c|c|c|c|c|c|c|}
\hline & $\begin{array}{l}\text { High } \\
\text { VR }\end{array}$ & 2 & 3 & 4 & 5 & 6 & 7 & 8 & 9 & $\begin{array}{l}\text { Low } \\
\text { VR }\end{array}$ & $\begin{array}{c}\text { Spread } \\
10-1 \\
\end{array}$ \\
\hline \multicolumn{12}{|c|}{ Panel A: Portfolio Characteristics } \\
\hline$\beta_{m k t}$ & 1.05 & 1.02 & 1.02 & 1.00 & 0.98 & 1.01 & 0.98 & 1.00 & 1.00 & 0.94 & \\
\hline t-statistic & 43.50 & 45.99 & 49.79 & 42.21 & 44.85 & 49.06 & 53.91 & 45.45 & 39.36 & 33.65 & \\
\hline$\beta_{S M B}$ & 0.99 & 0.90 & 0.87 & 0.90 & 0.82 & 0.84 & 0.84 & 0.83 & 0.78 & 0.95 & \\
\hline t-statistic & 26.10 & 25.22 & 22.94 & 22.06 & 18.27 & 32.03 & 27.82 & 22.73 & 16.83 & 24.85 & \\
\hline$\beta_{H M L}$ & 0.18 & 0.28 & 0.31 & 0.30 & 0.31 & 0.35 & 0.33 & 0.36 & 0.35 & 0.34 & \\
\hline t-statistic & 5.07 & 6.97 & 8.55 & 6.82 & 7.96 & 9.65 & 9.59 & 8.89 & 7.46 & 7.14 & \\
\hline$\beta_{M O M}$ & -0.05 & -0.08 & -0.07 & -0.05 & -0.06 & -0.04 & -0.02 & 0.00 & -0.02 & 0.03 & \\
\hline t-statistic & -1.70 & -1.74 & -1.79 & -1.06 & -1.79 & -0.98 & -0.56 & -0.15 & -0.47 & 0.74 & \\
\hline Size $(\$ B)$ & 0.79 & 0.86 & 0.96 & 1.00 & 1.06 & 1.09 & 1.09 & 1.04 & 1.17 & 1.03 & \\
\hline $\operatorname{VR}(24)$ & 2.04 & 1.13 & 0.83 & 0.65 & 0.52 & 0.41 & 0.33 & 0.26 & 0.19 & 0.12 & \\
\hline$\sigma_{e}^{2}\left(\%^{2}\right)$ & 225.25 & 163.59 & 153.00 & 151.95 & 145.69 & 140.27 & 137.75 & 135.20 & 134.84 & 135.48 & \\
\hline \multicolumn{12}{|l|}{ Number of Stock } \\
\hline Mean & 287 & 287 & 288 & 288 & 289 & 288 & 289 & 289 & 289 & 289 & \\
\hline Mininum & 159 & 158 & 161 & 164 & 158 & 160 & 161 & 163 & 159 & 158 & \\
\hline \multicolumn{12}{|c|}{ Panel B: Returns per cent per month } \\
\hline Average Return & 1.38 & 1.42 & 1.49 & 1.57 & 1.56 & 1.55 & 1.55 & 1.61 & 1.67 & 1.71 & 0.32 \\
\hline t-statistic & 4.16 & 4.59 & 4.88 & 5.18 & 5.39 & 5.33 & 5.33 & 5.42 & 5.68 & 5.78 & 3.47 \\
\hline Capm $\alpha$ & 0.31 & 0.39 & 0.46 & 0.54 & 0.56 & 0.53 & 0.55 & 0.61 & 0.67 & 0.72 & 0.41 \\
\hline t-statistic & 1.70 & 2.36 & 2.82 & 3.20 & 3.33 & 3.38 & 3.47 & 3.77 & 4.19 & 4.10 & 4.89 \\
\hline FF3 $\alpha$ & 0.04 & 0.08 & 0.14 & 0.23 & 0.25 & 0.20 & 0.23 & 0.28 & 0.35 & 0.38 & 0.34 \\
\hline t-statistic & 0.47 & 1.03 & 2.00 & 2.82 & 2.90 & 2.94 & 3.23 & 4.01 & 4.42 & 4.31 & 3.91 \\
\hline FF $4 \alpha$ & 0.10 & 0.16 & 0.21 & 0.28 & 0.31 & 0.24 & 0.25 & 0.28 & 0.36 & 0.35 & 0.26 \\
\hline t-statistic & 0.97 & 1.68 & 2.37 & 2.71 & 3.36 & 2.86 & 3.09 & 3.56 & 4.13 & 3.79 & 2.93 \\
\hline
\end{tabular}


Table 6: Size and Book-to-market adjusted returns for Equally-Weighted Decile Portfolios formed each year from January 1967 to December 2004 on the Variance Ratio of Residual Returns

The 24 month variance ratio is estimated each year from the residuals from Fama-French 3-factor model regressions estimated over the previous 60 months. The portfolio returns run from January 1967 to December 2004.

$V R(24)$ is the average of the 24-month variance ratios which are estimated from Fama-French 3-factor residuals over the previous 60 months The $\beta^{\prime} s$ are the loadings of the portfolio returns on the 3 Fama-French and the Carhart Momentum factors. Size is the time series mean firm size in billion \$. Panel B reports size and book-to-market adjusted returns. Panel $\mathrm{C}$ reports the intercepts $(\alpha)$ from regressions of size and book-to-market adjusted returns on the market excess returns (CAPM), the 3 Fama-French factors (FF3), and the 3 Fama-French factors plus the Carhart Momentum factor (FF4). The returns and $\alpha^{\prime} s$ are in per cent per month, and the $t$-statistics are adjusted for autocorrelation and heteroscedasticity.

\begin{tabular}{|c|c|c|c|c|c|c|}
\hline & $\begin{array}{c}\text { High } \\
\text { VR }\end{array}$ & 2 & 5 & 9 & $\begin{array}{l}\text { Low } \\
\text { VR }\end{array}$ & $\begin{array}{c}\text { Spread } \\
10-1 \\
\end{array}$ \\
\hline \multicolumn{7}{|c|}{ Panel A: Portfolio Characteristics } \\
\hline$\beta_{m k t}$ & 0.04 & 0.01 & -0.02 & 0.00 & -0.04 & \\
\hline t-statistic & 2.12 & 0.44 & -1.60 & 0.24 & -2.70 & \\
\hline$\beta_{S M B}$ & 0.11 & 0.02 & -0.03 & -0.04 & 0.05 & \\
\hline t-statistic & 3.69 & 1.10 & -1.45 & -1.92 & 1.67 & \\
\hline$\beta_{H M L}$ & -0.12 & -0.06 & -0.02 & 0.01 & 0.01 & \\
\hline t-statistic & -3.47 & -2.53 & -0.63 & 0.34 & 0.28 & \\
\hline$\beta_{M O M}$ & 0.08 & 0.03 & 0.06 & 0.09 & 0.11 & \\
\hline t-statistic & 3.63 & 1.72 & 4.20 & 3.97 & 4.52 & \\
\hline Size & 0.81 & 0.89 & 1.11 & 1.22 & 1.08 & \\
\hline $\operatorname{VR}(24)$ & 1.94 & 1.07 & 0.49 & 0.18 & 0.11 & \\
\hline $\mathrm{BM}$ & 0.91 & 0.88 & 0.88 & 0.87 & 0.89 & \\
\hline \multicolumn{7}{|l|}{ Number of Stocks } \\
\hline \multicolumn{7}{|c|}{ Panel B: Size and B/M Matched Returns, per cent per month } \\
\hline Adjusted Return & -0.19 & -0.20 & -0.15 & 0.00 & 0.04 & 0.23 \\
\hline t-statistic & -2.09 & -3.75 & -2.73 & -0.06 & 0.70 & 2.18 \\
\hline \multicolumn{7}{|c|}{ Panel C: Size and B/M Matched Risk Adjusted Returns, per cent per month } \\
\hline CAPM $\alpha$ & -0.23 & -0.21 & -0.13 & 0.01 & 0.07 & 0.30 \\
\hline t-statistic & -2.66 & -4.01 & -2.52 & 0.11 & 1.15 & 2.95 \\
\hline FF3 $\alpha$ & -0.17 & -0.17 & -0.11 & 0.02 & 0.07 & 0.24 \\
\hline t-statistic & -2.02 & -3.19 & -1.95 & 0.33 & 1.10 & 2.49 \\
\hline $\mathrm{FF} 4 \alpha$ & -0.25 & -0.20 & -0.17 & -0.07 & -0.04 & 0.21 \\
\hline t-statistic & -3.11 & -3.40 & -2.98 & -1.19 & -0.77 & 2.19 \\
\hline
\end{tabular}


Table 7: Properties of Equally-Weighted 5 by 5 Portfolios Sorted on $\sigma_{e}^{2}$ and Variance Ratios from January 1967 to December 2004. At the end of each year from 1966 to 2003, stocks are sorted into $\sigma_{e}^{2}$ quintile portfolios, where $\sigma_{e}^{2}$ is the variance of the residuals from Fama-French 3-factor model regressions estimated over the previous 60 months. Within each $\sigma_{e}^{2}$ quintile, they are further sorted into 5 variance ratio (VR) portfolios, where VR is defined as the ratio between the actual and the implied (assuming zero autocorrelation) variances of FF3 residuals over a 24-month period. The table reports Average returns and the intercepts $\left(\alpha^{\prime} s\right)$ from regressions of excess returns on the market excess returns (CAPM), the 3 Fama-French factors (FF3), and the 3 Fama-French factors plus the Carhart Momentum factor (FF4). The returns and $\alpha^{\prime} s$ are in per cent per month, and the $t$-statistics are adjusted for autocorrelation and heteroscedasticity.

\begin{tabular}{|c|c|c|c|c|c|c|c|c|c|c|c|c|}
\hline \multirow{8}{*}{$\begin{array}{l}\text { Lo } \sigma_{e}^{2} \\
2 \\
3 \\
4 \\
\text { Hi } \sigma_{e}^{2}\end{array}$} & \multicolumn{6}{|c|}{ Average Returns (\%) } & \multicolumn{6}{|c|}{ t-statistic } \\
\hline & $\mathrm{Hi}$ & & & & Lo & Spread & $\mathrm{Hi}$ & & & & Lo & Spread \\
\hline & VR & 2 & 3 & 4 & VR & $(5-1)$ & VR & 2 & 3 & 4 & VR & $(5-1)$ \\
\hline & 1.23 & 1.27 & 1.23 & 1.27 & 1.21 & -0.03 & 6.42 & 6.80 & 6.70 & 6.68 & 6.09 & -0.38 \\
\hline & 1.34 & 1.33 & 1.33 & 1.41 & 1.43 & 0.09 & 5.43 & 5.36 & 5.41 & 5.94 & 5.86 & 1.26 \\
\hline & 1.41 & 1.41 & 1.52 & 1.50 & 1.61 & 0.20 & 4.75 & 4.78 & 5.25 & 5.02 & 5.40 & 2.54 \\
\hline & 1.57 & 1.65 & 1.73 & 1.65 & 1.86 & 0.29 & 4.14 & 4.37 & 4.82 & 4.48 & 5.07 & 3.04 \\
\hline & 1.52 & 1.62 & 2.09 & 2.06 & 2.30 & 0.78 & 3.39 & 3.53 & 4.58 & 4.31 & 4.78 & 4.95 \\
\hline & \multicolumn{6}{|c|}{ CAPM Adj. Returns (\%) } & \multicolumn{6}{|c|}{ t-statistic } \\
\hline & $\mathrm{Hi}$ & & & & Lo & Spread & $\mathrm{Hi}$ & & & & Lo & Spread \\
\hline & VR & 2 & 3 & 4 & VR & $(5-1)$ & VR & 2 & 3 & 4 & VR & $(5-1)$ \\
\hline Lo $\sigma_{e}^{2}$ & 0.41 & 0.45 & 0.41 & 0.43 & 0.36 & -0.05 & 3.07 & 3.54 & 3.45 & 3.60 & 2.81 & -0.65 \\
\hline 2 & 0.40 & 0.40 & 0.40 & 0.48 & 0.50 & 0.10 & 2.70 & 2.80 & 2.80 & 3.58 & 3.59 & 1.36 \\
\hline 3 & 0.39 & 0.39 & 0.52 & 0.50 & 0.61 & 0.22 & 2.37 & 2.48 & 2.96 & 2.76 & 3.48 & 2.87 \\
\hline 4 & 0.45 & 0.53 & 0.63 & 0.56 & 0.79 & 0.34 & 2.04 & 2.42 & 2.95 & 2.59 & 3.45 & 3.64 \\
\hline \multirow[t]{4}{*}{ Hi $\sigma_{e}^{2}$} & 0.32 & 0.43 & 0.92 & 0.88 & 1.16 & 0.84 & 1.18 & 1.50 & 2.90 & 2.69 & 3.43 & 5.52 \\
\hline & \multicolumn{6}{|c|}{ FF3 Adj. Returns (\%) } & \multicolumn{6}{|c|}{ t-statistic } \\
\hline & $\mathrm{Hi}$ & & & & Lo & Spread & $\mathrm{Hi}$ & & & & Lo & Spread \\
\hline & VR & 2 & 3 & 4 & VR & $(5-1)$ & VR & 2 & 3 & 4 & VR & $(5-1)$ \\
\hline Lo $\sigma_{e}^{2}$ & 0.12 & 0.15 & 0.13 & 0.16 & 0.07 & -0.05 & 1.24 & 1.73 & 1.59 & 1.92 & 0.82 & -0.64 \\
\hline 2 & 0.07 & 0.07 & 0.04 & 0.16 & 0.13 & 0.06 & 0.75 & 0.72 & 0.44 & 1.83 & 1.56 & 0.81 \\
\hline 3 & 0.07 & 0.02 & 0.13 & 0.13 & 0.23 & 0.16 & 0.90 & 0.24 & 1.55 & 1.35 & 2.90 & 2.06 \\
\hline 4 & 0.08 & 0.18 & 0.34 & 0.21 & 0.44 & 0.36 & 0.72 & 1.88 & 3.33 & 1.83 & 3.77 & 3.67 \\
\hline \multirow[t]{4}{*}{ Hi $\sigma_{e}^{2}$} & 0.05 & 0.12 & 0.60 & 0.54 & 0.82 & 0.76 & 0.30 & 0.67 & 2.90 & 2.36 & 3.41 & 4.51 \\
\hline & \multicolumn{6}{|c|}{ FF3+MOM Adj. Returns (\%) } & \multicolumn{6}{|c|}{ t-statistic } \\
\hline & $\mathrm{Hi}$ & & & & Lo & Spread & $\mathrm{Hi}$ & & & & Lo & Spread \\
\hline & VR & 2 & 3 & 4 & VR & $(5-1)$ & VR & 2 & 3 & 4 & VR & $(5-1)$ \\
\hline Lo $\sigma_{e}^{2}$ & 0.16 & 0.18 & 0.14 & 0.17 & 0.10 & -0.06 & 1.94 & 2.27 & 2.02 & 2.32 & 1.19 & -0.75 \\
\hline 2 & 0.11 & 0.13 & 0.09 & 0.19 & 0.20 & 0.09 & 1.34 & 1.53 & 1.09 & 2.58 & 2.57 & 1.12 \\
\hline 3 & 0.13 & 0.10 & 0.20 & 0.20 & 0.24 & 0.11 & 1.40 & 1.21 & 2.25 & 2.23 & 2.76 & 1.32 \\
\hline 4 & 0.12 & 0.23 & 0.38 & 0.23 & 0.48 & 0.36 & 0.94 & 1.84 & 3.15 & 1.74 & 3.35 & 3.72 \\
\hline $\mathrm{Hi} \sigma_{e}^{2}$ & 0.24 & 0.34 & 0.71 & 0.61 & 0.84 & 0.60 & 1.20 & 1.44 & 2.78 & 2.29 & 3.33 & 3.83 \\
\hline
\end{tabular}


Table 8: Properties of Equally-Weighted 5 by 5 Portfolios Sorted on Variance Ratios and $\sigma_{e}^{2}$ from January 1967 to December 2004. At the end of each year from 1966 to 2003, stocks are sorted into variance ratio (VR) quintile portfolios, where VR is defined as the ratio between the actual and the implied (assuming zero autocorrelation) variances of the residuals from Fama-French 3-factor model regressions over a 24 month period estimated over the previous 60 months. Within each VR quintile, they are further sorted into $5 \sigma_{e}^{2}$ portfolios, where $\sigma_{e}^{2}$ is the variance of FF3 residuals estimated over the previous 60 months. The table reports Average returns and the intercepts $\left(\alpha^{\prime} s\right)$ from regressions of excess returns on the market excess returns (CAPM), the 3 Fama-French factors (FF3), and the 3 Fama-French factors plus the Carhart Momentum factor (FF4). The returns and $\alpha^{\prime} s$ are in per cent per month, and the $t$-statistics are adjusted for autocorrelation and heteroscedasticity.

\begin{tabular}{|c|c|c|c|c|c|c|c|c|c|c|c|c|}
\hline \multirow[b]{3}{*}{ Hi VR } & \multicolumn{6}{|c|}{ Average Returns (\%) } & \multicolumn{6}{|c|}{ t-statistic } \\
\hline & $\begin{array}{l}\text { Lo } \\
\sigma_{\rho}^{2}\end{array}$ & 2 & 3 & 4 & $\begin{array}{l}\mathrm{Hi} \\
\sigma_{\rho}^{2}\end{array}$ & $\begin{array}{c}\text { Spread } \\
(5-1)\end{array}$ & $\begin{array}{l}\text { Lo } \\
\sigma_{\rho}^{2}\end{array}$ & 2 & 3 & 4 & $\begin{array}{l}\mathrm{Hi} \\
\sigma_{\rho}^{2}\end{array}$ & $\begin{array}{c}\text { Spread } \\
(5-1)\end{array}$ \\
\hline & 1.22 & 1.29 & 1.55 & 1.49 & 1.43 & 0.21 & 5.98 & 4.91 & 4.68 & 3.80 & 3.08 & 0.59 \\
\hline 2 & 1.29 & 1.33 & 1.47 & 1.71 & 1.84 & 0.55 & 6.91 & 5.35 & 4.85 & 4.50 & 4.02 & 1.49 \\
\hline 3 & 1.22 & 1.29 & 1.48 & 1.61 & 2.06 & 0.84 & 6.63 & 5.30 & 5.33 & 4.55 & 4.57 & 2.23 \\
\hline 4 & 1.26 & 1.41 & 1.56 & 1.64 & 2.01 & 0.76 & 6.79 & 5.87 & 5.33 & 4.62 & 4.34 & 1.93 \\
\hline \multirow[t]{3}{*}{ Lo VR } & 1.21 & 1.40 & 1.59 & 1.77 & 2.34 & 1.13 & 6.21 & 6.03 & 5.69 & 4.96 & 4.90 & 2.79 \\
\hline & \multicolumn{6}{|c|}{ CAPM Adj. Returns (\%) } & \multicolumn{6}{|c|}{ t-statistic } \\
\hline & $\begin{array}{l}\text { Lo } \\
\sigma_{e}^{2}\end{array}$ & 2 & 3 & 4 & $\begin{array}{l}\mathrm{Hi} \\
\sigma_{e}^{2}\end{array}$ & $\begin{array}{c}\text { Spread } \\
(5-1)\end{array}$ & $\begin{array}{l}\text { Lo } \\
\sigma_{e}^{2}\end{array}$ & 2 & 3 & 4 & $\begin{array}{l}\mathrm{Hi} \\
\sigma_{e}^{2}\end{array}$ & $\begin{array}{c}\text { Spread } \\
(5-1)\end{array}$ \\
\hline Hi VR & 0.37 & 0.33 & 0.49 & 0.34 & 0.22 & -0.15 & 2.75 & 2.18 & 2.49 & 1.53 & 0.78 & -0.49 \\
\hline 2 & 0.47 & 0.40 & 0.44 & 0.58 & 0.67 & 0.20 & 3.71 & 2.69 & 2.75 & 2.59 & 2.21 & 0.66 \\
\hline 3 & 0.40 & 0.36 & 0.49 & 0.52 & 0.90 & 0.50 & 3.25 & 2.65 & 2.87 & 2.48 & 2.87 & 1.53 \\
\hline 4 & 0.43 & 0.49 & 0.56 & 0.57 & 0.84 & 0.42 & 3.58 & 3.54 & 3.16 & 2.77 & 2.78 & 1.26 \\
\hline \multirow[t]{3}{*}{ Lo VR } & 0.38 & 0.48 & 0.62 & 0.72 & 1.20 & 0.82 & 2.90 & 3.55 & 3.89 & 3.19 & 3.56 & 2.32 \\
\hline & \multicolumn{6}{|c|}{ FF3 Adj. Returns (\%) } & \multicolumn{6}{|c|}{ t-statistic } \\
\hline & $\begin{array}{l}\text { Lo } \\
\sigma_{e}^{2}\end{array}$ & 2 & 3 & 4 & $\begin{array}{l}\mathrm{Hi} \\
\sigma_{e}^{2}\end{array}$ & $\begin{array}{c}\text { Spread } \\
(5-1)\end{array}$ & $\begin{array}{l}\text { Lo } \\
\sigma_{e}^{2}\end{array}$ & 2 & 3 & 4 & $\begin{array}{l}\mathrm{Hi} \\
\sigma_{e}^{2}\end{array}$ & $\begin{array}{c}\text { Spread } \\
(5-1)\end{array}$ \\
\hline Hi VR & 0.09 & 0.00 & 0.18 & 0.04 & -0.05 & -0.14 & 0.89 & 0.04 & 1.95 & 0.36 & -0.25 & -0.66 \\
\hline 2 & 0.17 & 0.07 & 0.08 & 0.23 & 0.35 & 0.18 & 1.96 & 0.74 & 1.09 & 2.11 & 1.72 & 0.78 \\
\hline 3 & 0.11 & 0.01 & 0.10 & 0.19 & 0.58 & 0.47 & 1.32 & 0.08 & 1.09 & 1.92 & 2.78 & 1.96 \\
\hline 4 & 0.14 & 0.16 & 0.18 & 0.23 & 0.49 & 0.35 & 1.71 & 1.74 & 1.83 & 2.35 & 2.42 & 1.42 \\
\hline \multirow[t]{3}{*}{ Lo VR } & 0.08 & 0.15 & 0.21 & 0.34 & 0.86 & 0.78 & 0.94 & 1.69 & 2.46 & 2.94 & 3.62 & 2.87 \\
\hline & \multicolumn{6}{|c|}{ FF3+MOM Adj. Returns (\%) } & \multicolumn{6}{|c|}{ t-statistic } \\
\hline & $\begin{array}{l}\text { Lo } \\
\sigma_{e}^{2}\end{array}$ & 2 & 3 & 4 & $\begin{array}{l}\mathrm{Hi} \\
\sigma_{e}^{2}\end{array}$ & $\begin{array}{c}\text { Spread } \\
(5-1)\end{array}$ & $\begin{array}{l}\text { Lo } \\
\sigma_{e}^{2}\end{array}$ & 2 & 3 & 4 & $\begin{array}{l}\mathrm{Hi} \\
\sigma_{e}^{2}\end{array}$ & $\begin{array}{c}\text { Spread } \\
(5-1)\end{array}$ \\
\hline Hi VR & 0.13 & 0.05 & 0.20 & 0.09 & 0.21 & 0.08 & 1.51 & 0.57 & 1.82 & 0.70 & 0.98 & 0.37 \\
\hline 2 & 0.22 & 0.11 & 0.18 & 0.29 & 0.51 & 0.29 & 2.87 & 1.41 & 1.96 & 2.08 & 1.96 & 1.09 \\
\hline 3 & 0.12 & 0.07 & 0.17 & 0.26 & 0.71 & 0.60 & 1.50 & 0.89 & 1.83 & 2.32 & 2.69 & 2.07 \\
\hline 4 & 0.17 & 0.18 & 0.25 & 0.27 & 0.53 & 0.36 & 2.28 & 2.38 & 2.76 & 2.11 & 2.38 & 1.43 \\
\hline Lo VR & 0.10 & 0.21 & 0.23 & 0.35 & 0.88 & 0.78 & 1.16 & 2.53 & 2.63 & 2.59 & 3.51 & 2.87 \\
\hline
\end{tabular}


Figure 1: Theoretical Mispricing Return Premium, $B_{1}$, and Realized FF3 Alpha

Figure 1A plots annualized FF3 alphas against the estimated theoretical mispricing return premium for decile portfolios formed using the whole sample. For Figure 1B, the $10 \%$ of the securities with the highest premium estimates are removed from the sample before forming portfolios.

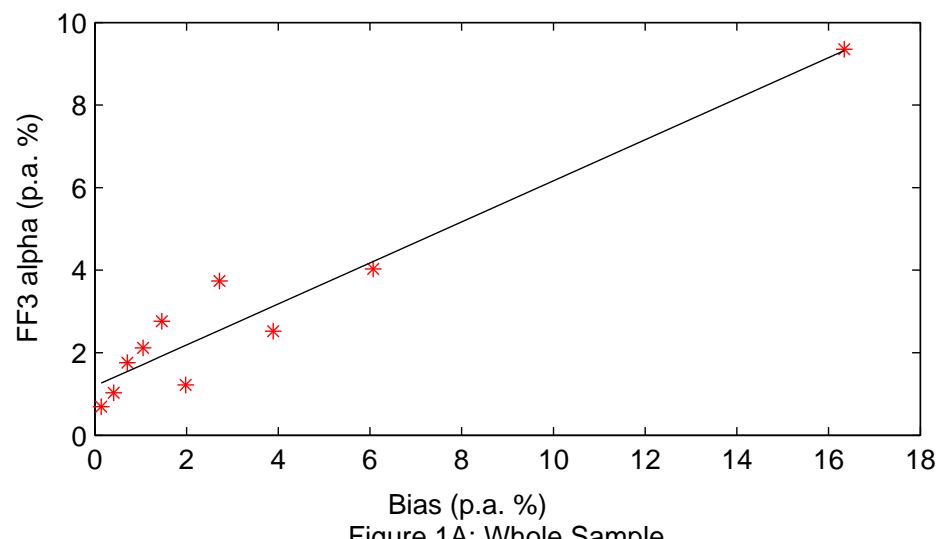

Figure 1A: Whole Sample

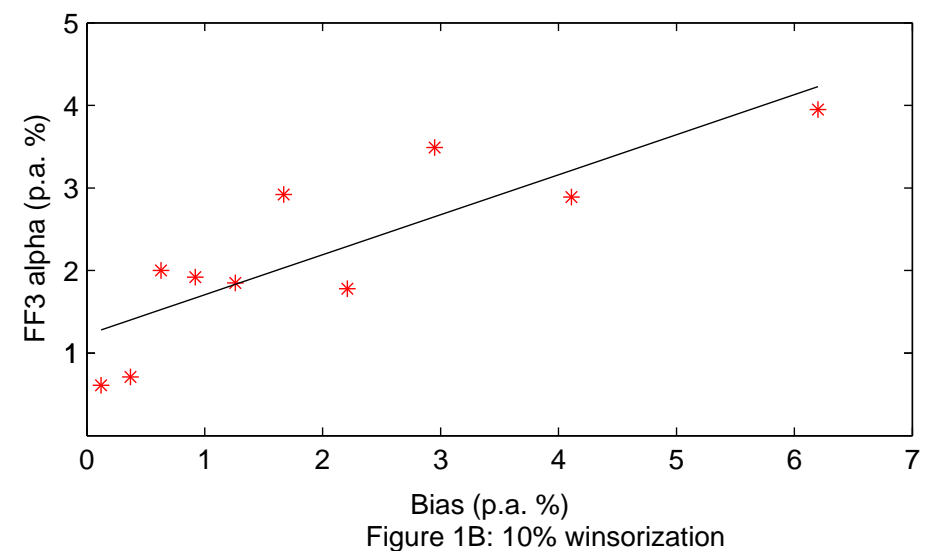

